\title{
Interdependencia cleptocrática: caso de estudio El Salvador
}

\author{
JUAN RICARDO GÓMEZ-HECHT*
}

Artículo recibido: 30 de agosto de 2015

Artículo aprobado: 8 de enero de 2016

Doi: http://dx.doi.org/10.12804/desafios28.2.2016.02

Para citar este artículo: Gómez-Hecht, J. R. (2016). Interpendencia cleptocrática: caso de estudio El Salvador. Desafíos, 28(2): 65-111. Doi: http://dx.doi.org/10.12804/desafios28.2.2016.02

\section{Resumen}

Actualmente las actividades del crimen organizado transnacional representan una de las mayores amenazas a la seguridad de la mayoría de estados en el mundo. Dichas actividades deterioran la confianza en las instituciones estatales, propagan la corrupción, amenazan el monopolio de uso de la fuerza del estado y debilitan la legalidad. Para que se fortalezcan y reproduzcan las organizaciones criminales, es necesario que se consolide una interdependencia cleptocrática entre ellas y los agentes estatales. Esta interrelación simbiótica y estratégica entre ambos actores, se materializa a través de la corrupción de los Agentes Estatalesy se objetiva en el hecho de que las Organizaciones Criminales Transnacionales logran obtener protección para el desarrollo de sus actividades ilicitas, mientras que los actores políticos involucrados logran consolidar y reproducir su poder con los recursos financieros provistos por las organizaciones criminales, estableciendo una codependencia entre ellos, en el interés mutuo del logro del control estatal para su propio beneficio. La presente investigación aplica esta teoría al caso de estudio de El Salvador con el objeto de determinar si en el país se ba establecido o se está estableciendo una relación de interdependencia cleptocrática.

* Docente de Seguridad Pública del Colegio de Altos Estudios Estratégicos, Comando de Doctrina y Educación Militar de la Fuerza Armada de El Salvador. Correo electrónico: ricardogomezhecht@gmail.com 
Palabras clave: crimen organizado, corrupción, El Salvador, Cleptocracia, nexo politico-criminal.

\title{
Kleptocratic Interdependence: A Case Study of El Salvador
}

\begin{abstract}
The activities of transnational organized crime represent one of the greatest threats to the security of the majority of states in the world. These activities deteriorate trust in state institutions, spread corruption, threaten the monopoly of the use of force and weaken the state and its legality. The consolidation of a kleptocratic interdependence between transnational criminal organizations and state agents is necessary for the former in order to strengthen and reproduce. This symbiotic and strategic relationship between the two actors is materialized through the corruption of state agents so that transnational criminal organizations are able to obtain protection for the development of their illegal activities, while the political actors involved in the scheme manage to consolidate and reproduce their power with the financial resources provided by the illegal actors. This article applies the theory to the case of El Salvador in order to determine whether the country has established or is establishing a kleptocratic interdependence.
\end{abstract}

Keywords: Organized crime, corruption, El Salvador, kleptocracy.

\section{Interdependência Cleptocrática: Caso de Estudo El Salvador}

\begin{abstract}
Resumo
Atualmente as atividades do crime organizado transnacional representam uma das maiores ameaças à segurança da maioria de estados no mundo. Ditas atividades deterioram a confiança nas instituições estatais, propagam a corrupção, ameaçam o monopólio de uso da força do estado e debilita ao mesmo e à legalidade. Para que as organizações criminais transnacionais se fortaleçam e reproduzam é necessário que se consolide uma interdependência cleptocrática entre elas e os agentes estatais. Esta inter-relação simbiótica e estratégica entre ambas os atores, se materializa através da corrupção dos Agentes Estatais e se objetiva no facto de que as Organizações
\end{abstract}


Criminais Transnacionais conseguem obterproteção para o desenvolvimento das suas atividades ilícitas, enquanto que os atores políticos envolvido conseguem consolidar e reproduzir o seu poder com os recursos financeiros fornecidos pelas organizações criminais, estabelecendo uma codependência entre eles, no interesse mútuo da conquista do controle estatal para o seu próprio benefício. A presente pesquisa aplica esta teoria ao caso de estudo de El Salvador com o objeto de determinar se o país se tem estabelecido ou se está estabelecendo uma relação de interdependência cleptocrática.

Palavras- chave: Crime organizado, corrupção, El Salvador, Cleptocracia, nexo politico-criminal.

"Ustedes saben que aquellos a quienes se considera gobernantes, dominan a las naciones como si fueran sus dueños, y los poderosos les hacen sentir su autoridad. Entre ustedes no debe suceder así. Al contrario, el que quiera ser grande, que se haga servidor de ustedes; y el que quiera ser el primero, que se haga servidor de todos." Evangelio según San Marcos 10, 35-45

"El error que se comete, no lo ve, es pensar que uno puede vivir en una sociedad corrupta sin ser uno mismo corrupto..."

George Orwell

\section{Introducción}

En el Siglo XXI las actividades del crimen organizado transnacional representan una de las mayores amenazas a la seguridad nacional e internacional de la mayoría de estados en el mundo. Dichas actividades deterioran la confianza en las instituciones estatales, propagan la corrupción, amenazan el monopolio de uso de la fuerza del estado y debilitan la legalidad. Para que las organizaciones criminales transnacionales se fortalezcan y reproduzcan es necesario que se consolide una interdependencia cleptocrática entre ellas y los agentes estatales. Esta interrelación simbiótica y estratégica entre ambos actores se materializa a través de la corrupción de los Agentes Estatales (AE) y se objetiva en el hecho de que las Organizaciones Criminales Transnacionales (OCT) logran obtener protección para el desarrollo de sus actividades ilícitas. Por su parte, Los AE involucrados logran con- 
solidar y reproducir su poder con los recursos financieros provistos por las OCT, estableciendo una codependencia entre ellos, en el interés mutuo del logro del control estatal para su propio beneficio. La presente investigación aplica esta teoría al caso de estudio de El Salvador con el objeto de determinar si en el país se ha establecido o se está estableciendo una relación de interdependencia cleptocrática.

La investigación pretende dar respuesta a este interrogante a través del análisis del fenómeno de la corrupción de alto nivel en el país y está orientada por la siguiente hipótesis: en El Salvador se está estructurando una relación de interdependencia cleptocrática en la medida que exista una interrelación simbiótica y estratégica entre los Organizaciones Criminales Transnacionales (OCT) y agentes estatales ${ }^{1}$ (AE) que genera efectos perniciosos para el país tanto en el ámbito nacional como en el ámbito internacional.

El Salvador ha sido seleccionado para efectuar el estudio de caso, dado que se encuentra en medio de la ruta de tránsito de todo tipo de actos ilícitos (droga, armas, lavado de dinero, contrabando y tráfico de personas), por lo tanto exhibe una considerable actividad del crimen organizado. Adicionalmente, el país muestra una fragilidad y debilidad de sus instituciones así como de sus sistemas político y judicial, situación que lo torna vulnerable a los actos de corrupción.

La importancia del trabajo de investigación radica en que determina -a través de la aplicación de la teoría de la interdependencia cleptocrática, propuesta por Kelly M. Greenhill ${ }^{2}$ (2009), y de un estudio comprensivo análisis empírico de caso- en qué medida en El Salvador se está estableciendo y reproduciendo esta interrelación simbiótica y estratégica entre las OCT y los AE. Además, el modelo elaborado para estudiar el fenómeno es una herramienta útil que puede ser aplicada a otros estudios de caso.

\footnotetext{
1 En este trabajo se entenderán por Agentes Estatales tanto a los actores políticos como a los funcionarios gubernamentales.

2 Kelly M. Greenhill es profesora de Ciencias Políticas y Relaciones internacionales de la Universidad de Tufts e Investigadora de la Escuela de Gobierno Kennedy de Harvard.
} 


\section{Metodología}

La investigación se ha apegado a la metodología para estudios de ciencias políticas propuesta por Stephen Van Evera (1997). En este sentido, se ha tomado en cuenta para la delimitación de la investigación, sus recomendaciones y conceptos en lo relativo a las herramientas básicas de inferencia científica y de metodología para el estudio de casos.

$\mathrm{El}$ análisis se ha realizado siguiendo las indicaciones propuestas por Kruger (2006), por medio de las cuales se ha determinado que los métodos analíticos idóneos a utilizar son los de evaluación estratégica y análisis de sistemas, dado que permitirán dilucidar el fenómeno de la relación de interdependencia cleptocrática entre las OCT y los AE en el país. Además, se efectuó un análisis crítico de dicha relación para procurar detectar sus factores claves, continuidades, cambios y tendencias, a la vez de comprender su complejidad por medio de un análisis en el que es considerado como un sistema dentro de sistemas.

Utilizando el método de análisis de sistema (Randers, 1980; Senge, 1990) se elaboró un modelo para determinar actores, relaciones y dinámicas de la teoría de interdependencia cleptocrática (anexo 1). A partir del modelo se infirió la hipótesis que orienta la investigación para posteriormente contrastar la misma con la realidad observable en El Salvador, a fin de verificar hasta qué punto el fenómeno se reproduce en el país, así como para detectar `congruencias e incongruencias entre lo esperado y lo observado.

La evaluación de la situación de corrupción en El Salvador se realizó a través de los informes que dan seguimiento a dicho fenómeno: el Barómetro Global de la Corrupción 2012, el Índice de Percepción de Corrupción 2012, el Indicador del Control de Corrupción del Banco Mundial de 2011, el Barómetro de las Américas de 2012 y el Índice de Estado de Derecho de 2012. Estos informes son considerados como los mejores indicadores para dimensionar la corrupción de alto nivel (Ho \& Huang, 2011; Ruhl, 2011). 
Además, se analizó el objeto de estudio a partir de hechos y datos reportados en los medios de comunicación social del país. Actualmente se considera en la academia que las notas periodísticas se convierten en un tipo de "lingua franca" de la sociedad, en la que moldean no sólo lo que ha pasado en determinada época y espacio, sino también lo que las personas han pensado que ha ocurrido, de acuerdo con los datos que se les proporcionan a través de los medios de comunicación (Knudson, 1993). En la presente investigación la mayoría de notas periodísticas citadas tienen su valor en el sentido en que las mismas son reportajes sobre hechos ocurridos y no análisis o valoraciones subjetivas sobre estos.

\section{Marco Teórico}

La investigación teóricamente se desarrolla alrededor de dos temas principales: el crimen organizado y la interdependencia cleptocrática, haciendo un especial énfasis en sus efectos perniciosos tanto nacionales como internacionales.

\subsection{El crimen organizado transnacional}

El concepto de Crimen Organizado (CO) es problemático dada la variedad de circunstancias, actividades y dinámicas que engloba. En la presente investigación el término define aquellas organizaciones que compartan las siguientes cinco características propuestas por Albanese (2008): 1) Una jerarquía organizada; 2) uso o amenaza del uso de fuerza para lograr sus objetivos; 3 ) logro de utilidades a través del crimen o actividades ilícitas; 4) uso de la corrupción para garantizar impunidad y; 5) existencia de una gran demanda pública por sus servicios o productos ofertados. El CO se torna transnacional cuando desarrolla "[...]sus actividades delictivas en zonas geográficas pertenecientes a varios Estado”(ONU, 2014).

El CO opera como una empresa cuyos únicos objetivos son obtener ganancias y sobrevivir. Además, opera a través de una fluida estructura de red; esta es simultáneamente intangible y penetrante, ubicua e invisible, presente en todos y en ningún lugar. Estas redes proveen 
a las organizaciones criminales de diversidad, flexibilidad, poca visibilidad, resiliencia y adaptabilidad. A su vez, son capaces de crear entramados de influencia por medio de la corrupción de miembros de las agencias de aplicación de la ley, funcionarios de gobierno y jueces para obtener protección, información e impunidad (Williams, 2001). Actualmente resulta evidente que no hay gobierno inmune al desarrollo del CO, ni sistema legal con capacidad suficiente para controlar su crecimiento, ni sistema financiero que esté exento de la tentaciones que ofrecen las inmensas ganancias que proveen sus actividades ilícitas (Shelley, 2001).

En el siglo XXI, la influencia de los Estados-Nación se encuentra en descenso y aparecen nuevos actores violentos operando en la ilegalidad, que desafían a los primeros y luchan entre ellos mismos. Las tendencias demográficas y medioambientales presentan un desafío a la sustentabilidad, seguridad y estabilidad del sistema internacional. El incremento poblacional provoca una enorme demanda en el medio ambiente, en el agua, la comida y suministros de energía. Estas áreas se verán afectadas por una encarnizada competencia e interrupciones y déficits de suministro, situación que las torna atractivas para las OCT, siempre en busca de oportunidades.

La mayoría del incremento de la población se dará en países en vías de desarrollo, los cuales, en su mayoría, muestran una limitada capacidad estatal y sus oportunidades de empleo se ven constreñidas. Estas circunstancias no solo generan problemas de inestabilidad, sino que alientan a jóvenes desprovistos de oportunidades a ingresar a estructuras de crimen o buscar una salida migrando hacia otros países legal o ilegalmente, alimentando de esta forma las redes de tráfico y contrabando de personas. Otra dimensión clave la representa el enorme potencial para interacciones perniciosas ente el crecimiento urbano desmedido y las crisis económicas, elevados niveles de desempleo y una débil e inadecuada gobernanza. La severidad de los problemas se incrementa por la interconectividad y las interacciones entre los principales actores. A su vez, la pobre gobernanza que afecta a algunos Estados se configura en una fuente de inseguridad, inestabilidad y desorden. En este entorno las OCT se tornan en actores 
de relevancia al aprovechar la interconexión legal, económica y geográfica que promueve la globalización (Williams, 2012a; Killebrew \& Bernal, 2010; Naim, 2003).

Bajo la influencia de los movimientos sociales contemporáneos y la globalización, las OCT aparecen como una seria amenaza a la seguridad (Đorđević, 2009). La globalización ha facilitado los diversos tipos de tráfico, ha empoderado a las empresas criminales y ha tenido consecuencias disruptivas que han creado incentivos para la criminalidad, habilitando a las OCT a compartir sus conocimientos y en algunos casos a colaborar entre sí (Williams, 2012a). Asimismo, las nuevas tecnologías de comunicación han generado nuevos modelos de negocio criminales, de amplia distribución, de redes en constante cambio de contactos personales y de fugaces alianzas para producir, mercadear, transportar o distribuir el comercio ilegal de personas o cualquier producto que genere lucro (Killebrew \& Bernal, 2010; Naim, 2003). La emergencia de sistemas globales financieros y de comercio han modificado el contexto en que la organizaciones criminales operan y ha alentado a grupos criminales que eran predominantemente domésticos a transnacionalizarse (Williams, 1994).

La globalización ha tenido consecuencias negativas en varias sociedades, generando pobreza, desempleo, inequidad y asegurando de esta manera un estable flujo de reclutas para las OCT. En zonas de exclusión social y económica los mercados ilegales e informales no sólo ofrecen una de las pocas oportunidades de empleo, sino que también proveen un cierto grado de gobernanza e inclusive provisión de bienes públicos. Ante la ausencia de oportunidades en la economía legal, las personas migran hacia lo ilegal.

Las OCT trabajan en el mercado global de forma similar a las corporaciones multinacionales. En este sentido, tienen las mismas prioridades estratégicas de aprovechar las ventajas y oportunidades para adquirir mayores ganancias (Williams, 2012a; Potter citado en Đorđević, 2009). Además, maximizan su libertad de acción o impacto y minimizan los efectos de los controles nacionales e internacionales entre las fronteras, o disminuyen sus riesgos, maximizan sus ganancias 
y crean nuevos mercados (Massari citado en Đorđević, 2009; Arquila \& Ronfelt, citados en Killebrew \& Bernal, 2010). La introducción de los contenedores intermodales no solo ha transformado la escala del comercio global al reducir los costos de transacción, sino también ha dificultado el control de las autoridades sobre los contenidos que transportan, facilitando a las OTC el ingreso de bienes ilegales (Williams, 2012a).

Las OTC gastan millones de doláres al año para socavar los gobiernos. Cuando la corrupción muestra ser insuficiente, se recurre a la intimidación y a la violencia. La idea es establecer áreas de influencia en que las OCT puedan operar sin restricciones, neutralizando el accionar de las autoridades locales. Estas organizaciones precisan " [...] del poder político para controlar las decisiones gubernamentales y modificar la legislación, rodeándose de un ambiente que les permita delinquir con menos riesgos” (La RED, 2011, p. 23).

Consecuentemente los sistemas electorales de algunos países son manipulados para el beneficio de organizaciones criminales y la corrupción e ineficacia de algunos sistemas judiciales entorpecen la capacidad de los gobiernos (DOD, 2012). Los recursos financieros de que disponen las OCT son inmensos; se estima que globalmente el narcotráfico genera entre 100.000 y 500.000 millones de doláres de ganancias al año, el tráfico de personas 32.000 millones de dólares y el tráfico de armas 10.000 millones de dolares (Congressional Research Service en Killebrew \& Bernal, 2010).

La disponibilidad de una gran cantidad de armas modernas y de elevado poder de fuego, habilitan a las OCT no solo a la comisión de otros crímenes, sino a enfrentar abiertamente a la policía y a las fuerzas armadas. La naturaleza burocrática de las agencias gubernamentales esta en desventaja ante la flexibilidad de estas redes de organizaciones criminales. En algunos países la lucha por el comercio ilícito ha escalado a tal grado que se ha convertido en una pelea por el control del poder entre estas organizaciones y los gobiernos (Killebrew \& Bernal, 2010). También los Estados se enfrentan a dos desafíos interconectados: el no poder satisfacer las necesidades y 
expectativas de su gente, y su incapacidad para generar la lealtad y fidelidad entre sus ciudadanos. Estas condiciones son propicias para la conformación de un entorno de anomia donde el capital social es reemplazado por el capital criminal, la violencia no es monopilizada por el Estado y las inhibiciones para realizar actos de barbarie desaparecen (Williams, 2012a).

En el ámbito nacional, las OTC ponen en peligro la estabilidad interna del Estado a través de la influencia de AE claves, ya sea por su incapacidad para confrontarlas efectivamente o por su involucramiento directo en las actividades criminales. Estas nefastas organizaciones implican una amenaza a la seguridad de la sociedad misma al atentar contra los valores morales y culturales, a la vez que generan desconfianza entre los mismos miembros que la conforman.

En el ámbito internacional, las OTC minan las normas e instituciones sobre la cuales se basa y funciona el sistema internacional. La inseguridad doméstica y la violencia que generan las OTC tiende a extenderse primero al ámbito regional y luego a la arena internacional (Đorđević, 2009). La situación se agrava si tomamos en cuenta que las OTC operan en y desde diferentes países soberanos, cada uno con su propia cultura, economía, gobierno, agencias de aplicación de la ley, justicia, fuerzas armadas, centros de transporte y rutas.

Las redes de OTC son componentes clave de los mercados ilícitos y el destruir algunas de estas organizaciones en red sólo conlleva una ruptura temporal del mercado (Killebrew \& Bernal, 2010; Williams 2012a). Las redes finacieras mundiales son esenciales para las OCT para el lavado y traslado de dinero. Según los expertos el lavado de dinero en el mundo asciende a 500.000 millones anuales (Wilson citado en La Red, 2012, p. 1).

En el siglo XXI la trasnacionalización del CO bien puede ser la máxima tendencia emergente en el entorno global de seguridad, desatando una guerra contra los Estados que claramente están perdiendo. En esta centuria la mayor división global no será ocasionada por la competencia entre diferentes ideologías, sino entre los Estados que 
defiendan la ley y el orden, y los que están dominados por intereses criminales (Naim, 2003; Killbrew \& Bernal, 2010; Williams, 2012a).

\subsection{La teoría de la Interdependencia Cleptocrática (IC)}

El concepto de interdependencia cleptocrática (IC) define un conjunto de interrelaciones y actividades de lucro y auto promoción doméstica e internacional entre las OTC y los AE. Estas actividades y relaciones sirven para fortalecer y enriquecer tanto a los criminales como a los AE corruptos, ayudándoles a consolidar su poder mientras aumenta su dependencia mutua. En su forma más extrema, las organizaciones criminales podrían llegar a compartir funciones de soberanía con el Estado (Greenhill, 2009).

La interrelación descrita se materializa en actos de corrupción; este último concepto ha sido abordado académicamente desde varias perspectivas: desde sus efectos en la calidad de gobierno (Rothstein, 2011), así como de ser constitutiva de una violación legal, de considerarse como incumplimiento de deber o como traición y secretividad, a ser concebido como inequidad. Además se ha abordado desde las teorías del interés público, económica y eclécticas (Underkuffler, 2009). $\mathrm{Al}$ abordar este tema, resulta importante destacar que la corrupción es un fenómeno complejo y diferenciado que encuentra soporte en entornos y entes que garantizan la impunidad y mitigan el carácter de la infracción (Rocha, Brown \& Cloke, 2011).

Académicamente se diferencian dos tipos de corrupción: la de alto nivel y la de bajo nivel. La primera hace referencia a la practicada por altos ejecutivos políticos y gubernamentales e involucra elevadas cantidades de dinero; sus principales causas son el bajo desarrollo económico y débiles agencias de aplicación de la ley. La segunda involucra funcionarios de menor nivel y pequeñas cantidades de dinero, y su principal causa son las trabas burocráticas (Johnson \& Sharma citados en Ruhl, 2011; Jain citado en Ho \& Huang, 2011).

La corrupción ha existido siempre, pero lo novedoso en este siglo es la inmensa amenaza en que se ha constituido para el orden mundial, 
dado el poder y alcance transnacional que las organizaciones criminales han logrado. Actualmente, numerosas zonas del mundo son controladas por organizaciones criminales y Estados criminalizados, cuya atención se centra en la promoción de la corrupción (Rotberg, 2009).

La teoría de la IC trata de una interrelación simbiótica y estratégica entre las OCT y los AE. La interrelación simbiótica se objetiva en el hecho en que ambos actores se benefician mutuamente: los OCT adquieren protección para realizar sus actividades ilícitas de parte de los AE y estos últimos se benefician de los recursos financieros que le son provistos por los primeros, con los cuales logran consolidar y reproducir su poder. Adicionalmente, adquieren mayores capacidades actuando en conjunto que las que cada uno tiene operando por sí solo. La interrelación deviene en estratégica en el sentido que ambos actores forjan una alianza a largo plazo con el objetivo claro de auto perpetuarse y privilegiar sus intereses, a la vez de lograr el control estatal para su propio beneficio.

La IC se caracteriza por 4 factores clave: 1) Una división funcional del control político y social entre los actores estatales y no estatales; 2) el privilegio del lucro privado sobre el bien público; 3) la ausencia o falta de rendición de cuentas legal y jurídica, y 4) alguna medida de fusión entre los ámbitos de lo licito e ilícito (Greenhill, 2009).

El concepto de IC se deriva de los conceptos de "alianzas estratégicas" (Williams, 1994) y del "nexo político-criminal" (Godson, 2003). Las primeras involucran estrechos vínculos operacionales, en los cuales los participantes tienen un interés en el futuro de cada uno, objetivos a largo plazo y significativas ventajas competitivas. Las alianzas estratégicas son la respuesta racional al surgimiento de los mercados globales. Estas no sólo minimizan el riesgo, sino que generan sinergia en el sentido en que los participantes alcanzan objetivos que por sí solos les serían vedados o los alcanzarían pero no con el mismo grado de efectividad y confianza. Las alianzas estratégicas se forjan entre las organizaciones criminales dado que se ven obligadas a cooperar entre sí y negociar con la estructura ilegal de poder al enfrentar los mismos problemas y obstáculos. También se pueden aprovechar las 
distintas habilidades, experticias y capacidades de que disponen cada una de las organizaciones, así como utilizar rutas probadas y métodos de tránsito y tráfico. Un hecho resulta innegable las OCT van a verse involucradas en cualquier alianza que les facilite su empresa ilegal (Williams, 1994).

En lo concerniente al "nexo político-criminal" es de destacar que las OCT no operan en el vacío así como no pueden únicamente operar en el ámbito ilegal. Las organizaciones criminales requieren de la asistencia, o por lo menos la aquiescencia tácita de actores dentro de los sistemas gubernamentales y económicos, a fin de funcionar efectivamente. Consecuentemente, la corrupción deviene en un instrumento invaluable para que las OCT minimicen sus riesgos y maximicen sus ganancias (Greenhill, 2009). En este orden de ideas, el $\mathrm{CO}$ no es un conjunto de actividades que existe fuera de la ley y el gobierno, sino que es integral a estos. Los participantes criminales pueden técnicamente estar fuera del gobierno, pero el nexo del cual forman parte se organiza alrededor y se conduce a favor de los intereses no solo de los empresarios criminales, sino también de las élites económicas y políticas. Este nexo político-criminal de colaboración entre el establecimiento político con el bajo mundo criminal se constituye en una de las amenazas más peligrosas a la calidad de vida en el mundo contemporáneo. Un factor clave en la habilidad de este nexo para mantener el poder es el hecho de que puede recurrir a la violencia y a la intimidación. Adicional al uso de la violencia por medio de los criminales, el nexo político-criminal puede movilizar a las fuerzas del Estado en caso de considerarlo necesario para alcanzar sus objetivos (Godson, 2003). El concepto de IC se basa en este nexo político-criminal. Sin embargo, se diferencia de este último dado que el enfoque principal de Godson es interno, mientras que la IC puede ser ya sea de naturaleza doméstica o internacional o ambos a la vez simultáneamente (Greenhill, 2009).

La IC tiene sus raíces en el entendimiento de la naturaleza y conducta de la cleptocracias. Estas últimas son gobiernos que se caracterizan por una corrupción ascendente y por privilegiar la fortuna personal y el poder político de los AE y la clase dominante a expensas de la 
población. Uno puede concebir la IC como una malévola interpretación del concepto de "interdependencia compleja" de Keohane y Nye (2000b) ${ }^{3}$. Este concepto enfatiza el significado de las complejas conexiones transnacionales entre los estados y las sociedades. Correspondientemente la IC se enfoca en las dinámicas clave que le son análogas entre AE corruptos y las OCT en el sentido que no solo forjan alianzas pero también cooptan sus métodos, sus organizaciones y su personal. El relativo balance de poder entre las alianzas va a cambiar con el tiempo y a través de sus relaciones. En los casos más extremos simplemente se convierten en uno, como en los casos de “captura del Estado" o la criminalización estatal (Greenhill, 2009).

El principal aporte de la IC al estudio del OCT es que brinda una explicación en la conformación del nexo político-criminal, a través de la corrupción, en el que los principales actores, el OCT y los AE, forjan una alianza estratégica para privilegiar sus intereses y logar el control estatal para su mutuo beneficio. También se enfoca en la interrelación simbiótica que aumenta las capacidades de ambos actores en sus ámbitos de actuación.

La limitación de la IC es que se enfoca en la corrupción de alto nivel, dejando de lado la corrupción de bajo nivel, que también genera efectos perniciosos y facilita a los principales operadores del OCT el superar trabas burocráticas.

\section{El modelo dinámico de la teoría de la IC}

Para facilitar la comprensión de la teoría de la IC y su posterior aplicación al estudio de caso de El Salvador, se dividirá está en tres partes: los actores principales y su interrelación dinámica, los efectos de la IC en el ámbito interno (nacional) y los efectos de la IC en el ámbito

\footnotetext{
3 El concepto de "interdependencia compleja" tiene tres características principales: 1 ) Múltiples canales interestatales, transgubernamentales y transnacionales conectan a las sociedades; 2) las agendas de las relaciones interestatales consisten de múltiples temas que no están ordenados en una jerarquía clara y consistente; 3) cuando prevalece la interdependencia compleja, las fuerzas militares no son utilizadas por los gobiernos contra otros gobiernos dentro de la región o sobre los temas (Keohane \& Nye, 2000b, p. 21).
} 
externo (internacional). La explicación de la teoría se efectuará utilizando un modelo elaborado para tal efecto, partiendo de las ideas expuestas por Greenhill.

\subsection{Actores principales de la IC y su interrelación dinámica}

Según lo dicten las circunstancias, el CO se relaciona con los entes estatales por medio de la confrontación, la infiltración o la corrupción (Brandão, 2008). En sentido contrario, los gobiernos pueden tratar el problema del CO por medio de la confrontación o la colusión (Williams, 2012b).

En el caso de la IC, los actores principales son las OCT y los AE. Ambos se relacionan y enlazan entre sí a través de la corrupción de los primeros para los últimos y la protección que a cambio brindan estos a las OCT. En esta interrelación los AE reciben soporte financiero de las OCT, lo que les permite consolidarse en el poder político y poder reproducir sus estructuras de apoyo.

En el caso de las OCT estas adquieren protección tanto al nivel del sistema gubernamental, como en el sistema económico. En el primero de los casos, los AE salvaguardan los intereses de las OCT, a la vez que se obstaculizan las agencias de aplicación de la ley y la justicia. En el sistema económico, los AE permiten a las OCT el lavado de activos, el efectuar sus inversiones y el que logren la legitimización de estas (figura 1).

\subsection{Efectos de la IC en el ámbito interno (nacional)}

El eje central de la IC lo constituye la interrelación de corrupción y protección que existe entre las OCT y los AE; esta va creciendo y reproduciéndose por el ansia de poder, lo que motiva a que las OCT contribuyan financieramente y con otras formas de apoyo para asegurarse de que sus allegados sean electos o designados a importantes cargos políticos. $\mathrm{Al}$ reproducirse esta situación, en el ámbito interno la ciudadanía comienza a perder confianza en sus instituciones; consecuentemente, al irse desilusionando con estas últimas y los $\mathrm{AE}$, 


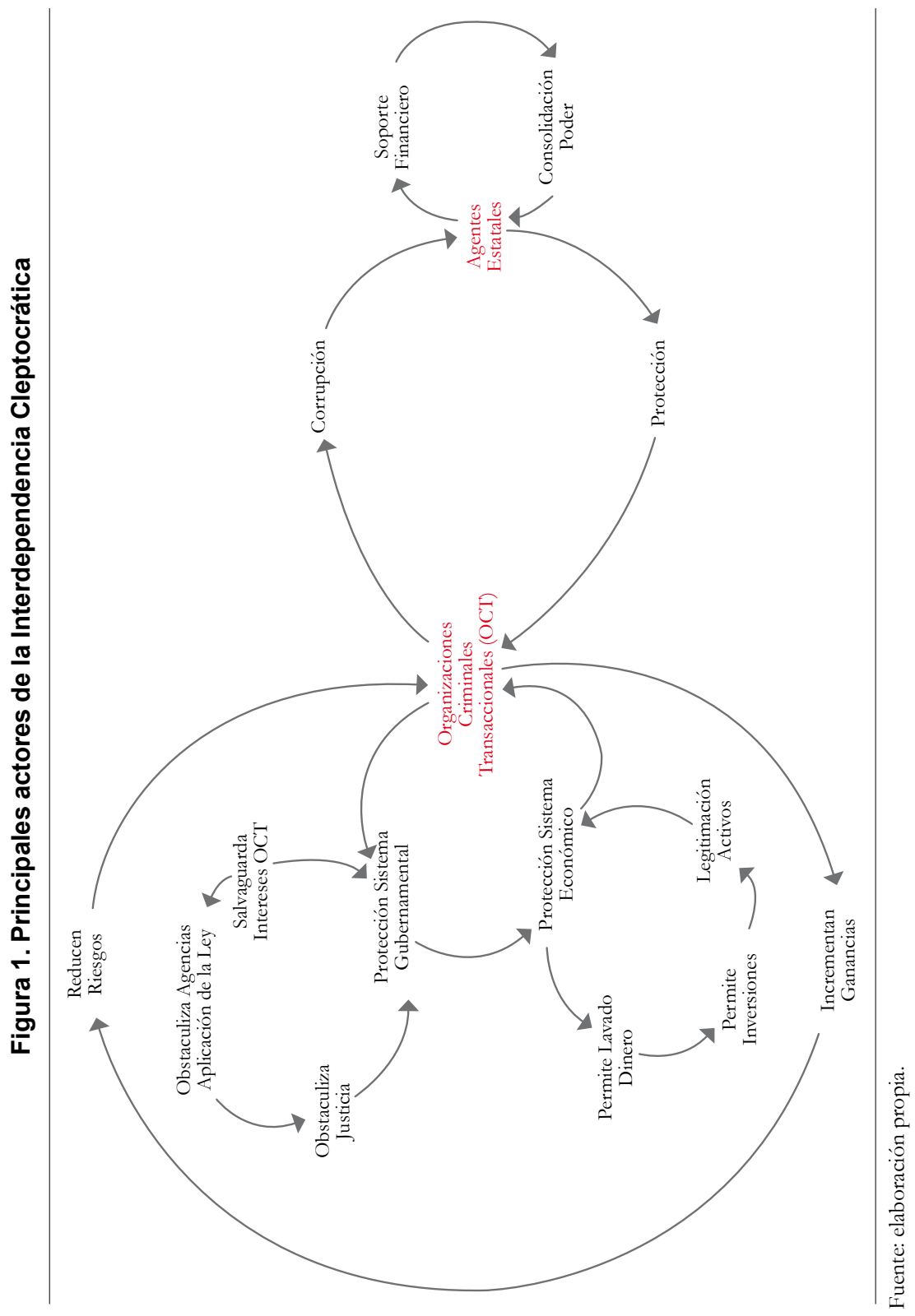


también pierde el interés por luchar contra la corrupción, aceptándola como necesaria del quehacer estatal y político. Inclusive en algunos casos la corrupción obtiene un cierto grado de legitimación social que apela a disposiciones culturales (Rocha, Brown \& Cloke, 2011). A su vez, el quehacer estatal privilegia el beneficio propio de las OCT y los AE y, en aras de esconder esta circunstancia, empieza a asentar un ámbito de ausencia de transparencia y rendición de cuentas; en la medida en que la IC se va fortaleciendo, se va garantizando la autoperpetuación de ambas partes intervinientes en el poder, estableciéndose una relación de codependencia entre las OCT y los AE, una vez se ha concertado el trato ilegal.

Es importante destacar que la relación entre las OCT y los estados débiles deviene en parasítica. Las primeras se ven atraídas hacia entornos donde el estado de derecho está ausente o imperfectamente aplicado, el cumplimiento de la ley y el control de fronteras es laxo, los sistemas regulatorios son débiles, los servicios públicos son poco fiables, la corrupción es endémica y el Estado puede capturarse relativamente fácil. Contrario a lo que se piensa, a las OCT no les conviene socavar aquellos Estados que pueden explotar y abusar para su propio beneficio; a estas organizaciones les interesa más el lucro que la política (figura 2).

\subsection{Efectos de la IC en el ámbito externo (internacional)}

Dos son los principales efectos derivados de la interrelación de IC entre los OCT y los AE. El primero es resultado de la codependencia que se forja entre esos actores, que internacionalmente se traduce en la expansión y consolidación de imperios criminales; una elevada rentabilidad es contingente con la habilidad de las OCT de aprovechar los mercados globales. El segundo deviene en que esta expansión criminal afecta el sistema internacional, ya de por sí trastocado por los efectos de la globalización y la transnacionalización del CO. Estas circunstancias permiten a las OCT el anhelado acceso a los mercados globales, lo que a su vez genera las condiciones para que se forjen relaciones de sinergia operacional, que permitan la explotación de redes internacionales ya existentes (figura 3 ). 
Figura 2. Efectos de la Interdependencia Cleptocrática en el ámbito interno

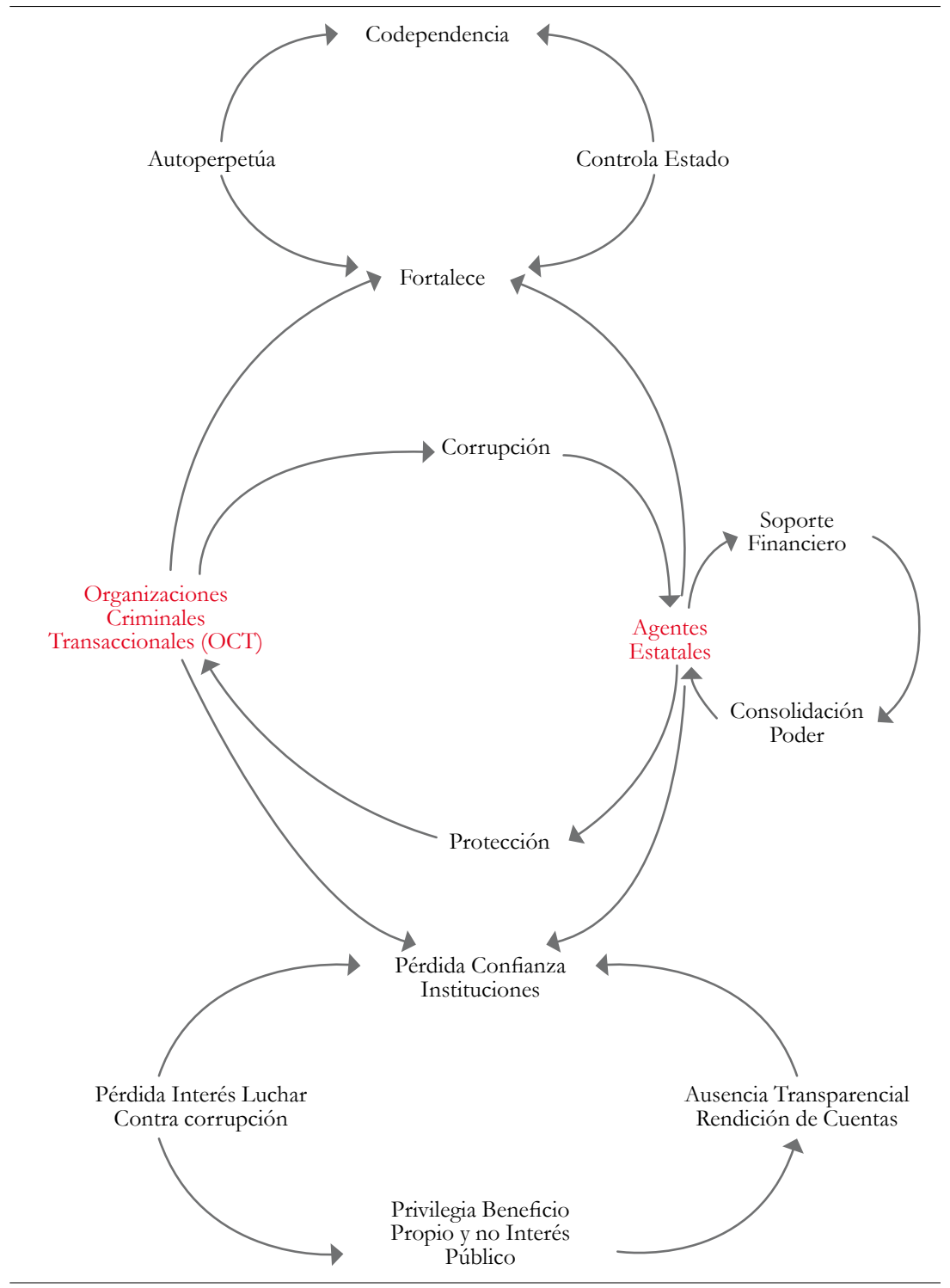

Fuente: elaboración propia. 
Figura 3. Efectos de la Interdependencia Cleptocrática en el ámbito externo internacional

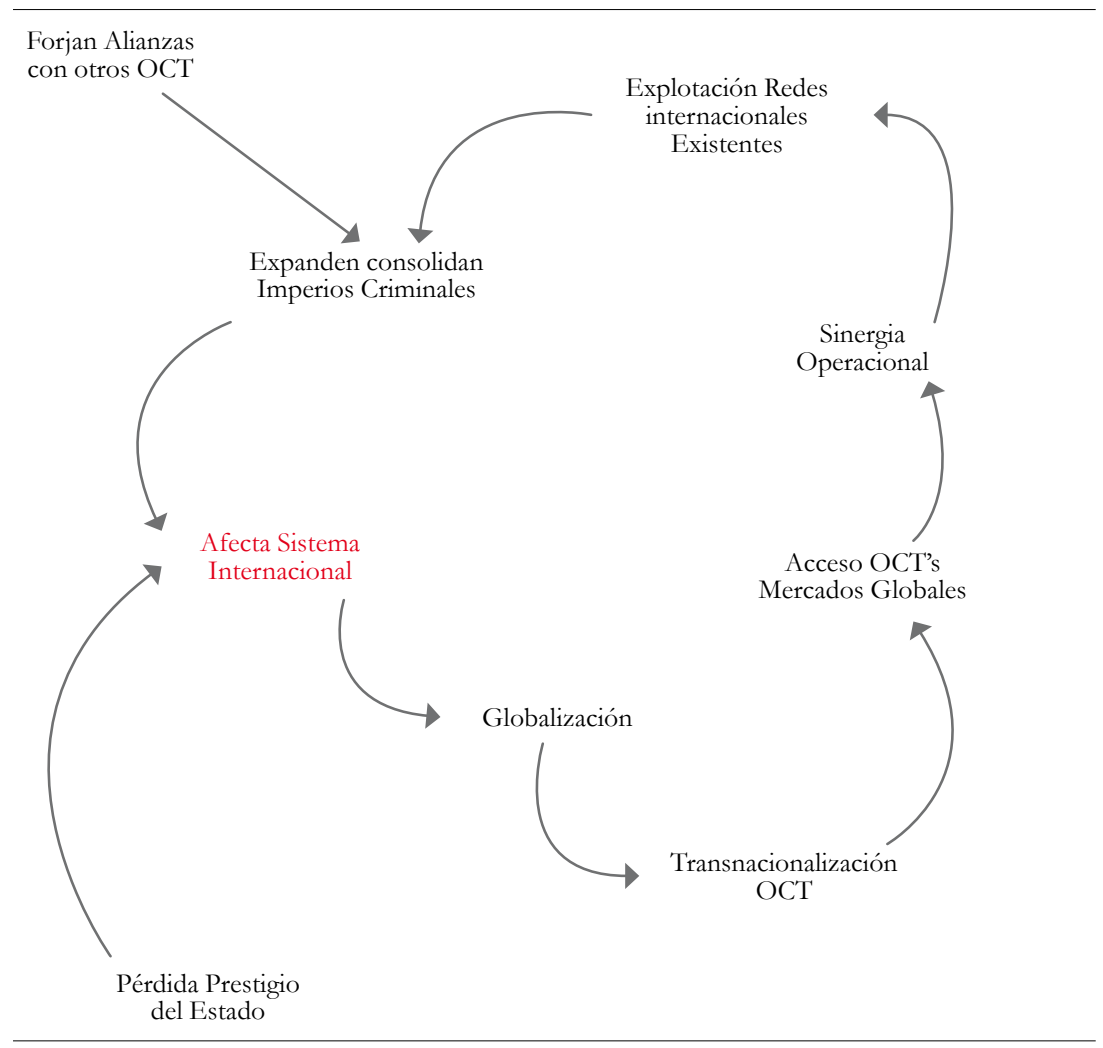

Fuente: elaboración propia.

\section{Aplicación del modelo IC: Caso de estudio El Salvador}

Para determinar si se está estructurando una relación de interdependencia cleptocrática en El Salvador, es menester aplicar a su realidad el modelo anteriormente descrito. Esto implica establecer tanto la presencia del OCT en el país, así como la existencia de una corrupción generalizada de AE. Asimismo, se torna necesario el establecer la interrelación simbiótica y estratégica entre el OCT y los AE, y los efectos perniciosos que esta dinámica genera para el país tanto en el ámbito nacional, como internacional. 


\subsection{Presencia de las Organizaciones Criminales Transnacionales (OCT) en El Salvador}

Un análisis de las OCT en El Salvador, dada su transnacionalización, requiere de una explicación en relación con el entorno de la actividad de estas organizaciones en la región centroamericana. Una confluencia de factores históricos, políticos, geográficos, económicos y sociales han determinado que la región se configure en un área de tránsito para todo tipo de tráfico ilegal.

El fenómeno de la presencia del CO en Centro América ha sido tema de estudio de diversos autores; estos lo han identificado como una de las máximas amenazas a la estabilidad democrática de los países del área, un enorme obstáculo para su desarrollo e inclusive un inmenso peligro para su viabilidad. También se han explorado la debilidad institucional y la inequidad económica que permiten que las OCT sigan pululando en el área. Igualmente amplia resulta la literatura que documenta el incremento del paso de la droga por la región y cómo la violencia que genera representa una afrenta al monopolio de uso de fuerza por parte de los Estados.

Actualmente se estima que $90 \%$ de todas las drogas ilícitas que tiene por destino Norteamérica transitan por la región. Agravando la situación, el relativo éxito de esfuerzos antinarcóticos en México y Colombia ha generado el "efecto vejiga", lo que ha provocado que las OCT incrementen sus operaciones en Centroamérica, región en la que los Estados disponen de menos recursos, instituciones débiles y otra serie de vulnerabilidades para enfrentar esta amenaza (Martens \& Philips, 2009; Arson \& Olson. 2011; Benítez Manault, 2012; Killebrew \& Bernal, 2012; Milian, 2008; La Red, 2012; Ellis, 2012; Meyer \& Ribando Seelke, 2012; UNODC, 2007, 2010, 2011, 2012).

La violencia instrumental, la corrupción y el lavado de dinero son características que definen la operatividad de las OCT. Existe abundante evidencia circunstancial que indica que en muchos países existen enlaces interdependientes entre estas organizaciones, la política y el sector público (Chêne, 2008). La existencia de OCT en El Salvador 
ha sido reconocida tanto por el Presidente de la República, como por las máximas autoridades de seguridad pública (Funes Cartagena, 2011; Membreño \& Flores, 2012). Asimismo, el descubrimiento de 14.6 millones de dólares enterrados en la campiña salvadoreña objetivó la envergadura de la presencia del CO en el país (LPG, 2011a).

El Salvador se ha visto afectado por ser un país de tránsito para todo tipo de tráfico. En lo que respecta al narcotráfico, han aumentado los decomisos de cocaína en el país. Solo en los meses de noviembre y diciembre de 2012 se llevaron a cabo tres decomisos de envergadura en que se incautaron 316 kilos (Marroquín, 2012a). También entre el 1 de enero de 2011 y el 14 de diciembre de 2012 se habían decomisado en la frontera de Peñas Blancas entre Costa Rica y Nicaragua la cantidad de 774 kilos de cocaína a furgones con placas salvadoreñas (LPG, 2012a).

Empeorando la situación, el país se ha tornado en un trampolín para la distribución de precursores químicos utilizados en la elaboración de droga sintética; así, en 2011 había en el país tres empresas de fachada importando 190 toneladas de estos químicos (Chávez, 2012c). Adicionalmente, el país se ha visto afectado por el tráfico de armas. En 2011 se hizo pública la existencia de una red dentro de la Fuerza Armada que había comercializado ilegalmente 8.000 granadas (Chávez, 2011) y un ex capitán del Ejército salvadoreño fue condenado a 31 años de prisión en los EEUU al haber sido capturado por agentes encubiertos de la DEA cuando supuestamente iba a vender armas de alto poder de fuego a las FARC (AP, 2011).

Por su parte, la amenaza de las pandillas adquirió una nueva dimensión cuando el Ministro de Justicia y Seguridad Pública reveló que la cantidad de pandilleros censados en la mitad de los municipios del país ascendía a 60.000 (Meléndez, 2012). Igualmente, un estudio calculó en 60 millones de dólares los ingresos anuales que las pandillas obtenían de sus actividades ilegales (Quintanilla, 2012). El poder de estas organizaciones quedó al descubierto cuando los homicidios en el país se redujeron a 2.300 en comparación con los del año anterior, después de que se formalizara una tregua entre pandillas rivales en marzo de 2012 (García, 2012). 
En El Salvador también se han detectado redes transnacionales de contrabando de cigarrillos, licor, ropa y perfumes (Flores, 2012a), así como de falsificadores de dinero (Membreño, 2012). Del mismo modo, la presencia de OCT en El Salvador ha sido un hecho estudiado por varios expertos en la materia (Arnson \& Olson, 2012; Farah, 2011).

\subsection{Estado de la corrupción en El Salvador}

Dada la naturaleza reservada y secreta tanto de la corrupción como de las actividades de las OCT, existe una limitada habilidad para poder establecer con certeza hasta qué punto la corrupción puede ser atribuida a estas últimas. Sin embargo, esta limitación no debe ser óbice para analizar la situación de dicho fenómeno en el país (Chêne, 2008). Aclarado este aspecto, la corrupción generalizada es un mal innegable en el país y ha sido señalada como uno de sus principales problemas (State Department, 2011); sobre todo se ha señalado que el país muestra significativa incidencia de corrupción de alto nivel (Ruhl, 2011).

El mismo ex Presidente de la República ha hecho público que en sus primeros tres años de gobierno había estudiado 307 casos con graves irregularidades; de estos, se han presentado 111 a la Fiscalía General de la República (FGR) por considerar que existen suficientes elementos de juicio para que esta inicie las respectivas investigaciones criminales, sin que a la fecha se conozca de estos resultado alguno (Romero, 2012). Esta situación quedó claramente reflejada en los resultados del Barómetro Global de Corrupción 2010/2011, en donde el 89\% de los encuestados consideraron como corruptos o extremadamente corruptos a los partidos políticos; el 88\% consideró lo mismo de la policía; el 78\%, de los funcionarios públicos; el 68\%, del sistema judicial, y el 63\%, de la Asamblea Legislativa. Así mismo, el 48\% de encuestados percibe que la corrupción en el país ha aumentado y el $47 \%$ considera que en este no existe ninguna institución que combata este flagelo (BGC, 2011). También El Salvador refleja un alto índice de corrupción en el Índice de Percepción de Corrupción (38) y ocupa el puesto 83 entre 176 países (IPC, 2012). 
En los Indicadores de Gobernanza del Banco Mundial 2011, el país obtuvo un percentil de control de corrupción de 52.1, lo que significa que está por encima de los países evaluados en ese rubro. Igualmente, de acuerdo al Barómetro de las Américas 2012, 37.7\% de encuestados no evaluó bien los esfuerzos en el combate de la corrupción del actual gobierno y $64.4 \%$ consideró que la corrupción de los funcionarios públicos en el país está muy (32.8\%) o algo (31.06\%) generalizada. El Índice de Estado de Derecho (WJP, 2012) también reveló que los encuestados asumen que existe corrupción en el Ejecutivo, la Legislatura y el sistema judicial, y que no se sanciona a los funcionarios de gobierno con mala conducta. En este sentido, la tasa de condenas en el sistema judicial es de menos del 5\% (State Department, 2011). Desde el año 2007, y a pesar de la generalización de la corrupción de alto nivel, solo se han procesado por ese delito dos casos: uno que involucra a un ex Ministro de Salud y un ex Subdirector General de la Policía Nacional Civil; otro en que participaron un ex Presidente y un Ex Administrador de la Administración Nacional de Acueductos y Alcantarillados.

En El Salvador se han aprobado la legislación y los mecanismos de seguimiento de los acuerdos internacionales contra la corrupción, además de crearse entidades fiscalizadoras para coadyuvar en esta lucha. Sin embargo, en la práctica estas iniciativas enfrentan limitaciones de recursos y el desafío de remontar una baja confianza ciudadana en las instituciones de control (PEN, 2011). En el país es notoria la obstrucción de proyectos legislativos por parte de AE que estén relacionados con el lavado de dinero, la extinción de dominio, la extradición, el financiamiento de campañas y de partidos políticos e iniciativas de transparencia y rendición de cuentas. Además, en El Salvador, desde hace mucho tiempo, los grupos de CO han tenido vínculos con políticos y con agencias de aplicación de la ley, pero últimamente la infiltración y corrupción de las instituciones estatales se ha tornado cada vez más complicada, debido al creciente rol de los carteles de tráfico de drogas (WOLA, 2011). 


\subsection{Actores principales de la IC en EI Salvador y su interrelación dinámica}

El análisis de los actores principales de la IC en El Salvador (las OCT y los AE) y su interrelación dinámica se hará a través de la aplicación del modelo elaborado (ver figura 1).

En lo que respecta al primero, su presencia obedece a que el país forma parte de múltiples cadenas de actores y rutas que estas organizaciones criminales utilizan para todo tipo de tráfico ilegal. Las funciones principales de las OCT salvadoreñas consisten en transportar los productos ilícitos y en proporcionar su protección durante su trayecto sobre territorio nacional. Esta situación se les facilita en vista de disponer de redes y contactos establecidos con anterioridad por medio de los cuales contrabandeaban otro tipo de productos, especialmente queso, armas y personas (Arnson \& Olson, 2012; Farah, 2011).

Estas organizaciones no solo operan en el territorio nacional, sino en todo el área centroamericana, a través del uso de sus compañías de transporte (Redacción de Nación, 2012a). Así mismo, en sus funciones subcontratan a otras organizaciones criminales, especialmente pandillas, para funciones específicas, como el sicariato o la protección. A estas organizaciones se les paga en especie, lo que ha provocado que las pandillas ingresen en el mercado del narcomenudeo (García, 2012b; Flores, 2012b; LPG, 2012b).

En lo que respecta a los AE, los antecedentes son bastante sombríos. Existen varios ejemplos de figuras políticas directamente involucradas en actividades ilícitas, sobre todo en el narcotráfico. Dos ex diputados de la Asamblea Legislativa se dedicaban a dicha actividad ilícita, mientras ostentaban su cargo público. Uno de ellos fue procesado y condenado a 29 años de prisión en los EEUU por transportar 36 toneladas de cocaína a dicho país (Wilgoren, 2006). El otro está recluido en un centro de detención migratoria en Arizona y sobre él pesan dos solicitudes de extradición de la justicia salvadoreña por lavado de dinero y soborno; también es investigado por la FGR por narcotráfico y por el asesinato de tres diputados salvadoreños perte- 
necientes al Parlamento Centroamericano en Guatemala (Velásquez \& Díaz, 2010). Este último caso es emblemático dado que los diputados fueron asesinados por policías y se vieron involucradas altas autoridades políticas y de seguridad pública guatemalteca. El móvil del crimen se vinculó al narcotráfico y a que uno de los diputados asesinados trasladaba en el vehículo en que se transportaban cinco millones de dólares en efectivo (Fernández \& Jara, 2010).

\subsubsection{Interrelación Simbiótica: vínculos de Corrupción y Protección entre los OCT y AE}

La interrelación entre ambos actores OCT y AE se dinamiza a través de la relación simbiótica que se entrelaza en vínculos de corrupción y protección (figura 4).

Figura 4. Interrelación Simbiótica entre OCT y AE

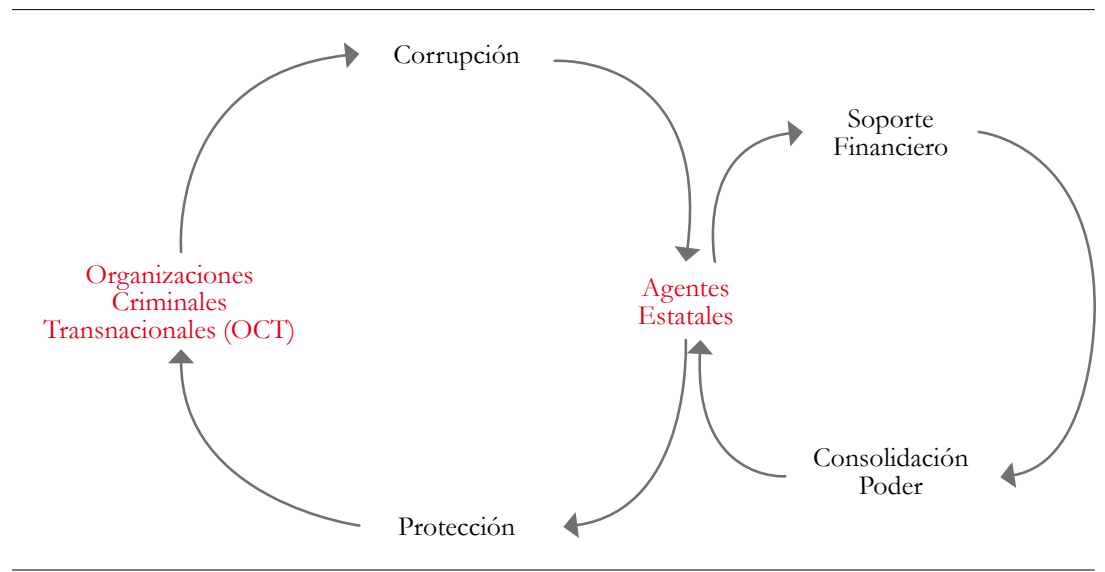

Fuente: elaboración propia.

4.3.2. Soporte Financiero por medio de la corrupción de las OCT a los $A E$ que les permite financiar sus campañas políticas y consolidarse en el poder

El soporte financiero de las OCT a los AE en El Salvador se orienta al financiamiento de campañas políticas locales y municipales, y se evidencia en la presencia de partidos políticos que no gozan de soporte popular y, sin embargo, continúan prevaleciendo sobre todo en 
aquellas áreas geográficas por donde pasan las rutas de tráfico ilegal (Arnson \& Olson, 2012).

El financiamiento de los partidos políticos es un aspecto crítico, dado que el sistema es permisivo y sin controles (PEN, 2011), no existe normativa que regule dicha actividad y por lo tanto la identidad de las personas e instituciones donantes se mantiene en secreto (Orellana, 2012). Adicionalmente, la Ley de Partidos Políticos que debe regular la materia se aprobó sin los suficientes elementos de fiscalización de fondos (Menjívar, Mejía \& Romero, 2013) y la estructura de poder es propensa a la injerencia de actores poderosos en las máximas instancias dada la débil institucionalidad (PEN, 2011). Así mismo es público que algunos partidos políticos reciben dinero y favores políticos a cambio de sus votos en la Legislatura (Aguilar, 2011). Este soporte ha permitido a ciertos $\mathrm{AE}$ consolidarse en el poder en algunos municipios del país. Igualmente, el 49\% (41) de los actuales diputados propietarios tiene 9 años o más de estar en la legislatura y de estos 21 están en esa palestra política por 15 años o más.

\subsubsection{Protección de los $A E$ de las OCT dentro del sistema gubernamental y el sistema económico}

En El Salvador los AE proveen protección a las OCT tanto dentro del sistema gubernamental como dentro del sistema económico, facilitándoles el incremento de sus ganancias y la reducción de riesgos (figura 5).

\subsubsection{Protección en el Sistema Gubernamental}

En lo que respecta al primero, este se objetiva en la salvaguarda de los intereses de las OCT. En El Salvador los ejemplos de este tipo de situación abundan: el Centro de Intervención de las Telecomunicaciones, a pesar de contar con los recursos necesarios, ha tomado más de dos años en iniciar sus actividades y ha realizado algunas operaciones sin contar con la participación de la policía (Cabrera, 2012a; Salguero, 2012; LPG, 2012c). Los procesos de extradición permanecen inmovilizados en la Corte Suprema de Justicia (CSJ), a pesar de la presión 
Figura 5. Dinámica de Protección de los AE de las OCT

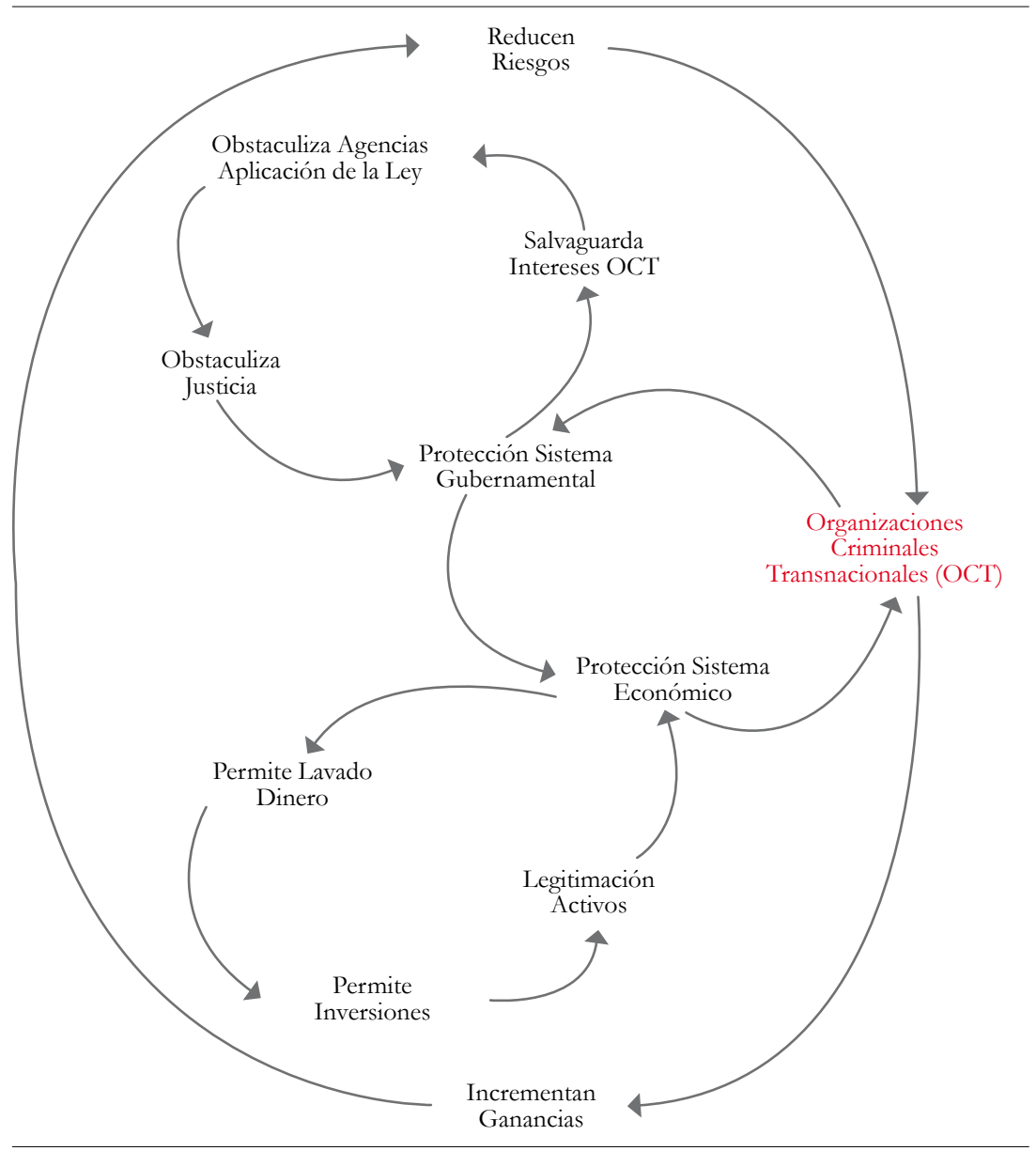

Fuente: elaboración propia.

ejercida por los EEUU para que se agilicen (Delhi, 2009). Una de las primeras acciones del Presidente de dicha curia, nombrado ilegalmente y luego sustituido, fue coincidentemente el de solicitar los expedientes de dichos casos (López \& Iraheta, 2012). Finalmente una serie de propuestas de ley para despojar de sus bienes al CO permanecen inmóviles en la Legislatura (Marroquín, 2012b).

La corrupción en el país ha obstaculizado las agencias de aplicación de la ley. Son conocidos varios casos de personajes ligados al narcotráfico a los cuales se les ha posibilitado darse a la fuga al habérseles avisado de 
su inminente captura, o se han obstruido sus investigaciones (AFP, 2007; Redacción de la Nación, 2012b; LPG, 2011b). Además, se han señalado muchas deficiencias en la FGR, la cual en muchas ocasiones se ha rehusado a actuar en casos en que está involucrado el CO (Arnson \& Olson, 2011; Baires Quezada, 2011). Un caso ejemplar es el de un reconocido narcotraficante que tiene varios casos abiertos en la FGR desde hace cuatro años, de los cuales ninguno ha rendido fruto alguno (Velásquez, 2012). Adicionalmente, a pesar del incremento en el decomiso de drogas y dinero, y el conocimiento de redes criminales dedicadas a todo tipo de tráfico, existen pocas capturas de relevancia, puesto que, por lo general, los únicos detenidos son los miembros operativos más no los cabecillas. Otra situación preocupante la constituyó la encarnizada lucha política librada durante este año para tratar de nombrar un Fiscal General que respondiera a determinados intereses; esta situación generó que el país durara más de dos meses sin un nombramiento para el cargo (Soriano y Rivera, 2012). Análogamente, preocupa el hecho de que, a pesar de haberse advertido del incremento de importación de precursores químicos de 310 kilos en 2010 a 52.140 kilos durante el 2011, las autoridades no hayan actuado sobre esa información (Chávez, 2012a). El problema se agudiza cuando todo el sistema se debilita al no pagarse a tiempo el salario de policías y se falla en la protección de los testigos (Iraheta, Quintanilla, Segovia \& Mendoza, 2012).

La protección dentro del sistema gubernamental también implica el obstaculizar la justicia. En este ámbito, en El Salvador se ha señalado una sustancial corrupción en el sistema judicial, que contribuye a altos niveles de impunidad y socava el estado de derecho y el respeto público por el poder judicial (State Department, 2011). El grado de corrupción es tal que en el año 2012 la CSJ informó que estaban siendo procesados 1.284 abogados por sobornos y fraude. Además, se estaban procesando 1.085 jueces, datando algunos de estos casos desde 1995 (Ávalos, 2012a). El caso emblemático de corrupción lo constituye el caso de un alto dirigente político ligado al anterior gobierno, que solicitó a uno de los ex diputados acusados de narcotráfico la cantidad de 500.000 dólares para liberarlo de cargos en El Salvador (Baires Quezada \& Martínez, 2009). 
Los problemas empeoran al encontrarse el sistema totalmente saturado. A manera de ejemplo, las diversas Salas de la CSJ acumulan 5.259 expedientes en mora (Magaña, 2012a) y los Juzgados Especializados, que conocen en materia de CO, han recibido 10.997 casos de homicidio entre los años de 2009 y 2012, y tienen bajo su poder casos de 7,956 personas acusadas por extorsión (Chávez, 2012b). La sobrecarga de trabajo es tal, que estos tribunales cerraron sus puertas en señal de protesta en septiembre de 2012 (Ávalos, 2012b).

Mucho más peligroso resulta la debilidad institucional y la poca independencia e imparcialidad del sistema judicial frente a los poderes políticos y fácticos (DPLF y FESPAD, 2012). Asimismo, fue preocupante la crisis institucional desencadenada en el país entre abril y agosto de 2012, al negarse la Asamblea Legislativa a cumplir con un fallo de la CSJ, declarando inconstitucional la elección anticipada de los Magistrados y del Fiscal General, y desatando el consecuente limbo jurídico. Esta situación en opinión de la Relatora de Naciones especialista en el tema "[...] socavó gravemente la independencia del Órgano Judicial y el principio de separación de poderes” (Magaña, 2012b).

\subsubsection{Protección en el sistema económico}

La protección brindada a las OCT también se extiende al sistema económico. La economía dolarizada de El Salvador y su ubicación geográfica lo convierten en un refugio ideal para las OCT. A pesar que el país está catalogado como una jurisdicción de preocupación en lo que respecta al lavado de dinero, durante el año 2011 solo se fueron procesados judicialmente 11 casos por lavado de dinero y solo se lograron 4 condenas por este delito (State Department, 2012). La venta de drogas y la corrupción de AE son los principales delitos predecesores del lavado de activos. El Salvador no cuenta con una estrategia integral para el combate de esta amenaza ni una estructura de coordinación que articule los esfuerzos de las entidades competentes en la materia (La Red, 2012).

En el país existen fuertes vínculos a través de las OCT entre el mercado formal e informal, lo que permite que estas puedan realizar 
inversiones y legitimar sus activos. Bajo el amparo de los AE se utilizan compañías de fachada, hoteles, compañías inmobiliarias, compra de propiedades agrícolas, compra de apartamentos, empresas de lavado de autos, concesionarias de carros usados, discos, bares, restaurantes, agencias de viajes, las remesas, la importación y exportación de productos, el transporte de carga y operaciones pitufo para "blanquear" dinero (State Department, 2012; Arnson \& Olson, 2011). Así mismo, algunos grupos criminales salvadoreños están invirtiendo dinero en otros países como Cuba, Honduras y Nicaragua en propiedades cerca de la costa, plantas procesadoras de lácteos, préstamos de dinero a bajos intereses, hotelería y turismo (EDH, 2011a; EDH, 2011d).

La complejidad de detectar estas operaciones es enorme. Durante el año 2012 hasta noviembre en El Salvador se habían recibido 3,522.4 millones de dólares en concepto de remesas a través de 12,582,321 transacciones bancarias (EDH, 2012). Además, la mayoría de transacciones son realizadas a través de testaferros. En uno de los casos un empleado de un narcotraficante local, que ganaba 278 dólares quincenales, era dueño de 19 camiones de transporte (EDH, 2011b); en otro, un testaferro recibió la comisión de 750,000 dólares por la compra de un inmueble a su nombre (EDH, 2011c).

Las inversiones realizadas por las OCT permiten la legitimación de activos. No se dispone de un estimado de cuánto dinero se lava en el país, pero del análisis de unos pocos casos se puede apreciar que la suma es considerable. El supuesto líder de la organización criminal más fuerte del occidente del país, pasó de tener una empresa con activos de 49,000 dólares en 1995, a reportar ingresos en los siguientes 5 años por 30 millones de dólares (EDH, 2011c). Otra empresa que se dedica al empeño de prendas de oro abrió 15 sucursales por todo el país en menos de tres años y exportó entre los años 2004 y 2007 oro por valor de 136 millones de dólares (Suchit, 2012). Así mismo, un informe de la embajada norteamericana realizado en 2008 estimaba que entre 7 millones y 11 millones de dólares fueron lavados en el país a través de las remesas locales a las sucursales de Western Union (Embajada de los EE.UU El Salvador, 2012). Adicionalmente, en los últimos años, sobre todo en San Salvador, se han construido 
una gran cantidad de edificios de apartamentos, los cuales tienen un nivel de ocupación muy bajo, a pesar de representar inversiones millonarias. También la policía reporta que en los últimos tres años ha decomisado en procedimientos anti drogas USD 16'937.237, así como 229 vehículos (Marroquín, 2012c).

\subsection{Efectos de la IC en el ámbito interno de El Salvador (nacional)}

Los efectos de la IC en el ámbito interno se vertebran sobre la columna conformada por la interrelación de las OCT y los AE en su dinámica de corrupción/protección y la consecuente codependencia que se forja entre ellos en aras del logro de su propio beneficio (figura 2 y figura 6 ).

Uno de los principales efectos en el ámbito nacional de la IC lo constituye la pérdida de confianza en las instituciones. De acuerdo con el Barómetro de las Américas, en El Salvador , un 39.3\% de los encuestados consideraron que los tribunales de justicia no son garantes de un juicio justo y un $37 \%$ manifestó no tener o tener poca confianza en el sistema de justicia (LAPOP, 2012). También, un 37.5\% afirmó no tener o tener poca confianza en la Asamblea Legislativa; mientras un $29 \%$ afirmaba lo mismo en relación con el gobierno, y un $32.9 \%$, en relación con la FGR. El 33.9\% afirmó no tener o tener poca confianza en relación con la policía; el 34.1\%, en relación con la CSJ; el $39.3 \%$, en relación con la municipalidad y el $56.6 \%$, en relación con los partidos políticos.

El deterioro de la confianza en algunas instituciones es obvio si comparamos los resultados obtenidos en las encuestas para El Salvador de Latinobarómetro de los años 1996 y 2010. De acuerdo con estos datos, la desconfianza de la población en las instituciones ha aumentado en puntos porcentuales de la siguiente manera: el poder judicial en 19.2 puntos (de $57.40 \%$ a $76.10 \%$ ); los partidos políticos en 11.8 puntos (de $71.10 \%$ a $82.90 \%$ ); la Asamblea Legislativa en 10.3 puntos porcentuales (de $63.30 \%$ a $73.60 \%$ ); en la policía en 9.1 puntos $(60 \%$ a $69.1 \%$ ). En sentido contrario, la desconfianza ha disminuido en puntos porcentuales en: la administración pública en 4.2 puntos (de 
Figura 6. Dinámica de los Efectos de la IC en el Ambito Nacional

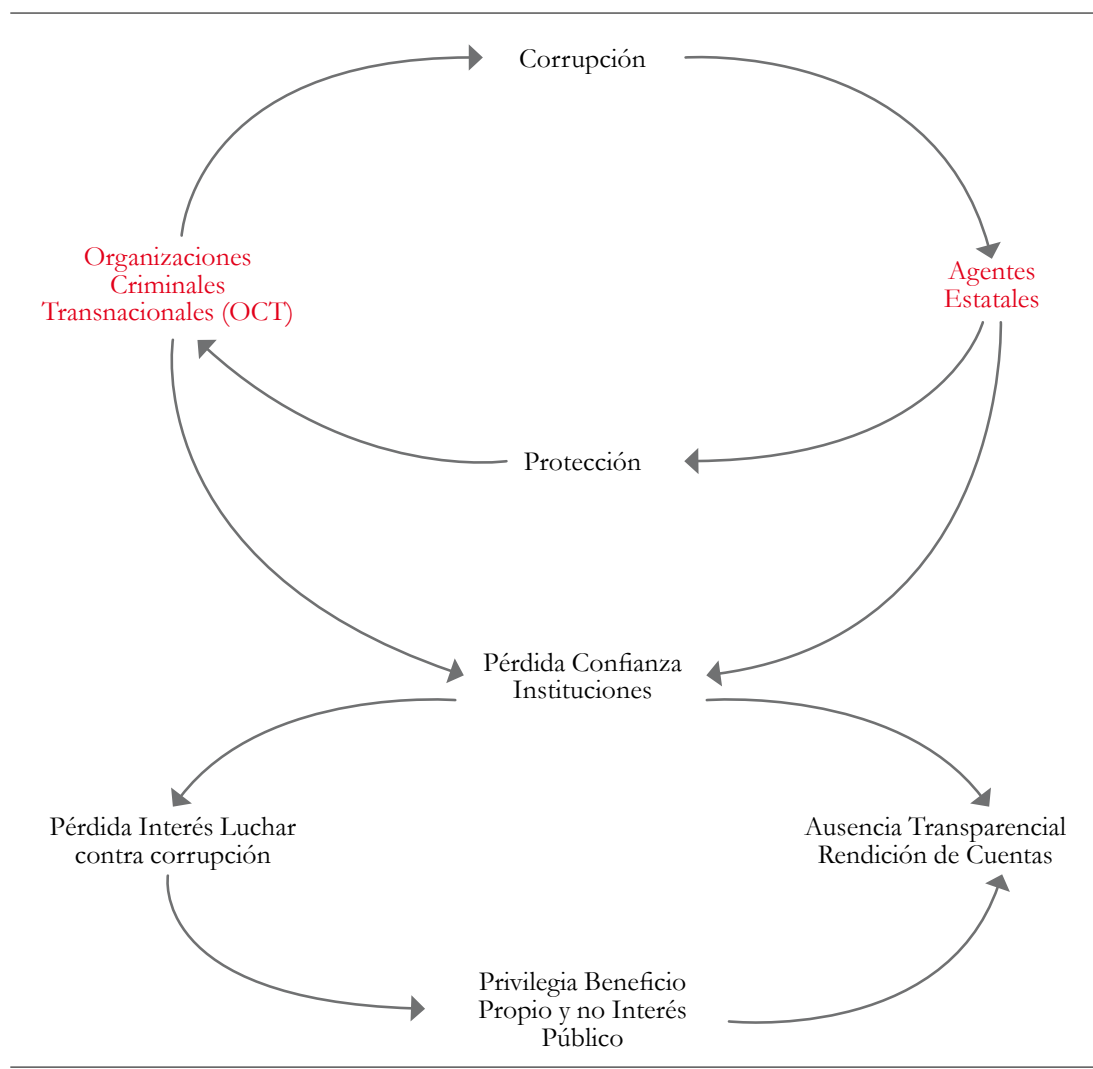

Fuente: elaboración propia.

63\% a 58.80\%); en las Fuerzas Armadas en 14.9 puntos (de 58.70\% a $43.80 \%$ ) y en el gobierno en 23.1 puntos (de $65.30 \%$ a $42.20 \%$ ) (Latinobarómetro, [en línea]). También la pérdida de confianza en las instituciones se refleja en el hecho de que en el referido instrumento, solo entre 2010 y 2011 El Salvador disminuyó en 4 puntos porcentuales en lo que respecta a los encuestados que manifestaron su apoyo a la democracia (de 59\% a 55\%) y en la encuesta de 2011 solo un $12 \%$ de los encuestados consideró que la democracia en el país había mejorado y la principal carencia que se le identificó fue la reducción de la corrupción (Latinobarómetro, 2011. pp. 29, 40 y 41).

Otro efecto que se señala de la IC es la pérdida de interés por parte de la población en la lucha contra la corrupción. Este efecto no se percibe en El 
Salvador; al contrario, la reacción ciudadana para exigir sus derechos ha venido incrementándose. Este hecho se refleja en el resultado del Informe de Latinobarómetro 2011 (2011), en el cual el 71\% de los encuestados consideraron que los ciudadanos exigían mucho o bastante sus derechos. El éxito de este despertar de conciencia cívica en la población y la articulación de colaboración entre organizaciones de la sociedad civil, se vio reflejado con la derogatoria del Decreto 743. Este decreto pretendía maniatar a la Sala de lo Constitucional, requiriendo que las resoluciones sobre constitucionalidad fueran tomadas por unanimidad. El mismo fue derogado ante el masivo rechazo de la población. También la sociedad civil se expresó con masivas demostraciones ante la crisis institucional que se desató a mediados de año por la confrontación entre la Asamblea Legislativa y la CSJ. Toda esta actividad, mucha de la cual fue promovida a través de las redes sociales, no pasó desapercibida, llegando inclusive a denominarse a estas redes el "nuevo cuarto poder" y ser considerado como uno de legados más importantes del año pasado (Morales, 2012). Así mismo, los medios de comunicación han denunciado públicamente irregularidades en la administración de la cosa pública.

Otro vestigio de la IC es que se privilegia el interés propio de los OCT y los $A E$ y no el interés público. Encontrar prueba directa sobre este punto resulta complicado; sin embargo, esta situación se puede inferir del análisis de la existencia de privilegios. En esta dirección, el informe de Latinobarómetro (2011) señala que 66\% de los encuestados indicó que "los ricos" cumplen menos con la ley y solo el $25 \%$ consideró que se gobierna a favor de todo el pueblo. Adicionalmente, la circunstancia de gobernar a favor de intereses propios y de la corrupción fue reconocida por parte de la Embajada de EEUU en el país como una de las causas de la división del anterior partido en el gobierno (Embajada de EE.UU El Salvador, 2009).

Igualmente el establecimiento de la IC se refleja en la ausencia de transparencia y rendición de cuentas. El Salvador en esta materia es evaluado por la Encuesta de Presupuesto Abierto 2010 con una calificación de 37, lo que significa que el país provee mínima información al público en sus documentos presupuestarios. En el país no existe voluntad 
política en estos temas; a pesar de que se aprobó la Ley de Acceso a la Información Pública, ha transcurrido más de un año y no se ha nombrado a los integrantes de su ente rector (Velásquez, 2012). También muchas de las instituciones no están haciendo pública toda la información que la ley les requiere (Cabrera, 2012b). Además, la falta de transparencia en el país es reconocida como uno de los principales problemas para la consolidación del Estado de derecho, la rendición de cuentas y el balance de poder dentro del sistema (Córdova Macías \& Cruz, 2010).

Finalmente, el otro efecto de la IC consiste en que deviene en una relación estratégica a largo plazo. Al consolidarse la IC, está se autoperpetúa y se genera la codependencia entre las partes intervinientes, teniendo ambas como último objetivo el control estatal (figura 7). Esta situación es difícil

\section{Figura 7. Interrelación Estratégica entre los OCT y los AE}

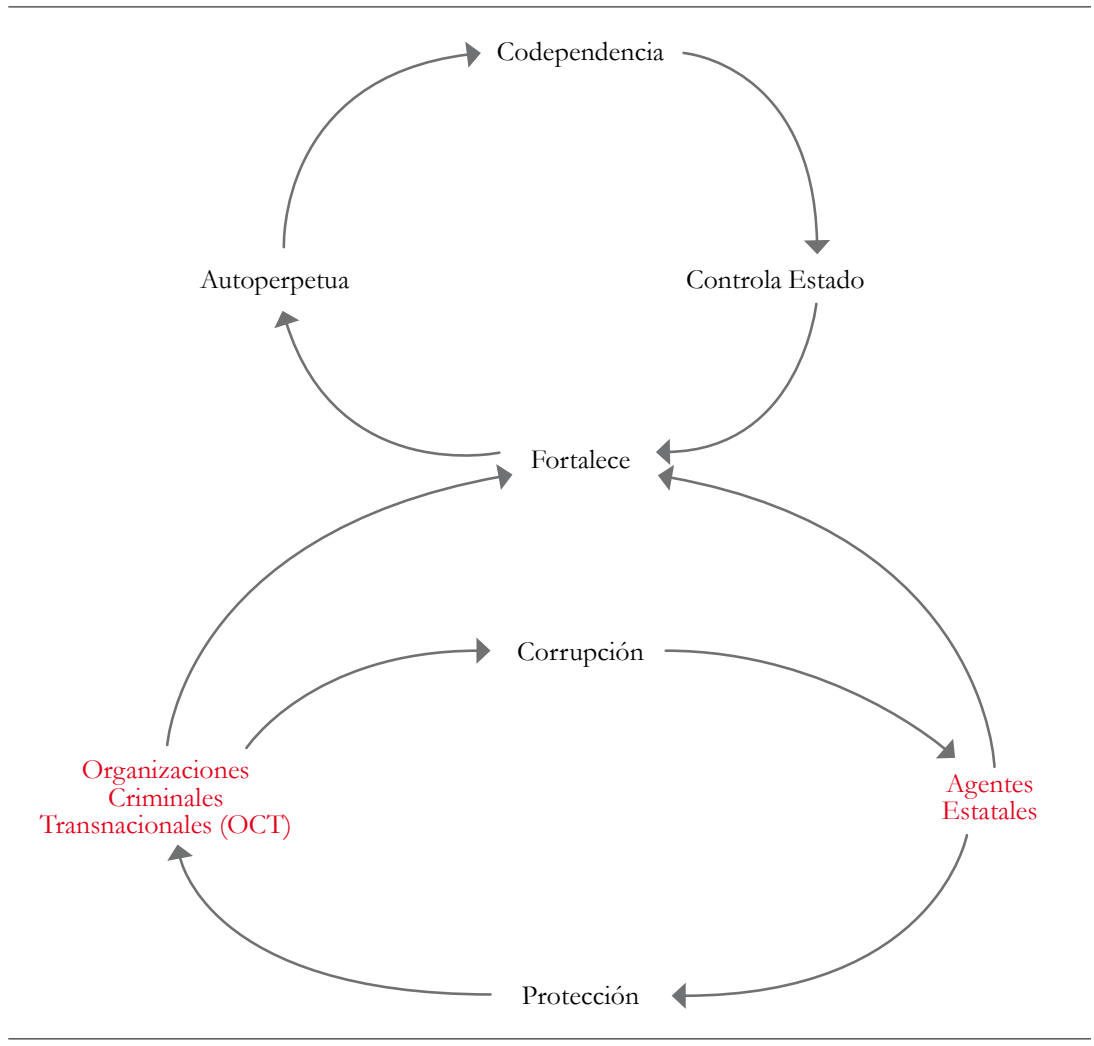

Fuente: elaboración propia. 
de percibir en El Salvador; sin embargo, es alarmante el crecimiento que el crimen organizado ha tenido en el país. Un prestigioso servicio privado de inteligencia clasifica a El Salvador con elevada presencia tanto de CO como de corrupción (AEGIS Defence services, 2012) y como se ha señalado, este no puede reproducirse sin la venia o ayuda de los $\mathrm{AE}$, por lo tanto existen elevadas posibilidades de que se éste forjando la IC.

\subsection{Efectos de la IC en el ámbito externo de El Salvador (internacional)}

La IC afecta el sistema internacional, debido a la compleja interdependencia que existe entre todos los actores que operan dentro del mismo (figura 3); lo que ocurre en una nación repercute en otras, aunque no existan fronteras en común (PEN, 2011). En el caso de la IC, en la esfera internacional, las OCT forjan alianzas estratégicas entre sí. Esta circunstancia ha favorecido que la región centroamericana se convierta en una especie de "enorme estación de servicio" para el tráfico de todo tipo de ilícitos, permitiendo el acceso de las OTC a los mercados globales (La Red, 2011; Bunck \& Ross Fowler, 2012).

En El Salvador, al igual que en los otros países centroamericanos, las OCT logran la sinergia operacional al aprovechar la experticia local y las redes de tráfico preexistentes, y a la vez inundan el país con sustanciales cantidades de dinero, proporcionando los medios para corromper a los AE.

En lo que respecta a las alianzas entre las OCT, ambos ex diputados vinculados al narcotráfico estaban ligados a organizaciones foráneas. Uno (el condenado a 29 años de prisión) era el jefe operativo de una de las más poderosas organizaciones guatemaltecas, que a su vez estaba ligada al Cartel del Golfo mexicano (Equipo de Investigación, 2007). El otro (involucrado en el asesinato de los diputados salvadoreños) estaba vinculado con la organización criminal basada en Jutiapa, Guatemala (EDH, 2010; El Faro, 2007). 
Adicionalmente, un ex presidente de la República ha reconocido que el Cartel de los Zetas había infiltrado a la policía y al ejército con el objeto de adquirir armas y explosivos, así como su experticia para ejecutar operaciones de riesgo en México, (Romero \& Gómez, 2011). Esta afirmación surge en el marco de la Cumbre de Seguridad en Centroamérica (junio, 2011), luego de que un ex policía salvadoreño muriera en un enfrentamiento armado contra el ejército en México (2010) y que granadas del ejército salvadoreño fueron utilizadas en atentados contra el Consulado de los EEUU en Monterrey (2008) y la empresa Televisa (2009) (EDH, 2011e; Valencia Caravantes, 2011). Además, autoridades guatemaltecas dieron a conocer que Los Zetas estaban reclutando pandilleros para que generarán caos en la ciudad capital y distraer las acciones y recursos de la policía y ejército lejos de las áreas de tráfico (AP, 2012). También se dio a conocer que dicha organización criminal había entrenado pandilleros salvadoreños en el Petén con el objeto de ponerlos bajo su servicio (Arnson \& Olson, 2012).

Otro efecto de la IC en el plano internacional es que, en la medida en que esta se va estableciendo en determinado país, este comienza a perder prestigio internacionalmente. En el caso de El Salvador, el país fue incluido por primera vez, en septiembre de 2011, en la lista de mayores países de tráfico de drogas por la administración Obama (WH, 2011). Todo lo expuesto anteriormente ha contribuido a que las OCT, sobre todo las mexicanas, expandan y consoliden sus imperios criminales obteniendo según se estima ganancias por valor de 39 mil millones de dólares anuales (Fantz, 2012).

\section{Conclusiones}

La presente investigación tuvo por objeto aplicar la teoría de la IC al caso específico de El Salvador, a fin de establecer si en el país dicha interrelación se ha establecido o se está reproduciendo. Sobre este aspecto se puede concluir que en El Salvador existen condiciones tanto objetivas como subjetivas para la estructuración y/o reproducción de la IC. Lo anterior se sostiene sobre la base de la evidencia expuesta a lo largo de la investigación, donde se ha podido comprobar cómo el 
empoderamiento que el proceso de globalización ha brindado a las OC ha permitido su transnacionalización, constituyéndose estas en una seria amenaza a la seguridad de todas las naciones, pero sobre todo de aquellas que presentan mayor vulnerabilidad, dada sus pocos recursos y débil institucionalidad. A su vez, las operaciones de estas organizaciones criminales, facilitadas por alianzas estratégicas, socavan las bases sobre las cuales se asienta el sistema internacional. Estos efectos perniciosos se generan en ámbitos domésticos nacionales pero rápidamente trascienden a las esferas regional y global, dificultándose seriamente su control por las diferencias de soberanía, leyes y de agencias de aplicación de la ley.

Los motivos expuestos permiten concluir que la transnacionalización de las OC y su empoderamiento es una tendencia que continuará presente en el ámbito internacional y será difícil de eliminar; sin embargo, sí se puede lograr administrar si se toman las decisiones, se dotan los recursos, se ejecutan las acciones correctas y se aborda el mismo por lo menos desde una perspectiva integral y regional.

Desafortunadamente, El Salvador se encuentra en medio de una vorágine de factores históricos, políticos, geográficos, económicos y sociales que favorecen el establecimiento y/o reproducción de la IC. No sólo se ubica en una de las áreas de mayor tráfico ilegal de todo tipo en el mundo, sino que se encuentra todavía en una etapa de transición hacia la democracia en su más amplio sentido, donde las antiguas estructuras no han sido aún superadas y las nuevas todavía no se encuentran lo suficientemente arraigadas para surtir sus efectos.

Dos situaciones innegables deben ser motivo de preocupación: la comprobada existencia en el país de las OCT y la presencia de una corrupción generalizada, ya que ambos son componentes sine qua non para el establecimiento y reproducción de la IC. En este sentido se advierte, ante la confianza que la ciudadanía otorgó en las encuestas citadas a lo largo del trabajo, que los AE más propensos a aliarse con las OCT se encuentran en el estamento político y con menos intensidad en los funcionarios de gobierno. Así mismo, tratándose la IC de corrupción de alto nivel, se aminora la probabilidad de que 
las temidas pandillas sean actores protagónicos de esta interrelación, debido a que si éstas recurren a la corrupción, esta será de bajo nivel.

Importante es recordar que ambos tipos de corrupción no pueden abordarse de la misma forma, pues cada uno debe ser tratado desde diferentes perspectivas y con diferentes medidas e instrumentos para lograr la efectividad deseada. Dentro de este marco, si no se toman las acciones pertinentes, esta situación continuará desarrollándose en el país con los consecuentes efectos negativos en su gobernanza y gobernabilidad. Advertido lo anterior, los esfuerzos para contrarrestar esta amenaza no deben hacerse esperar, comenzando por la toma de conciencia del mismo. A su vez, los esfuerzos deben centrarse en acabar con la impunidad de los AE y de las OCT tanto salvadoreñas como internacionales que han venido operando en el país, ya sea en alianza, individualmente o subcontratadas.

Otra tarea prioritaria debe ser superar las vulnerabilidades detectadas. Estas se potencian en un país como El Salvador, con limitada movilidad social y donde el más seguro camino al ascenso social lo constituye el dedicarse a actividades ilegales o a la depredación de los bienes estatales o su aprovechamiento para el beneficio propio. La debilidad institucional y la baja confianza de la ciudadanía en las instituciones del país son elevadas. En este aspecto el esfuerzo debe orientarse a mejorar la transparencia y rendición de cuentas de los AE, a la vez de establecer controles adecuados para evitar que las OCT permeen las instituciones, la economía legal y el financiamiento político. Igualmente, se deben fortalecer las agencias de aplicación de la ley y el sistema judicial, garantizándosele a este plena independencia para poder actuar imparcialmente y brindar pronta justicia. El gobierno y actores políticos deben mostrar su voluntad de coadyuvar en este esfuerzo, aprobando la legislación necesaria y dotarlas de todos los mecanismos y recursos que garanticen su aplicación.

Un aspecto esperanzador que aparece reflejado en la investigación es la toma de conciencia cívica de la ciudadanía, la cual ha descubierto el poder de organizarse y ha buscado la manera de defender sus derechos y exigir probidad a sus gobernantes y políticos. Igual avance 
han mostrado los medios de comunicación social, los cuales están comenzando a desarrollar el periodismo investigativo y a denunciar las irregularidades que encuentran en el desarrollo del mismo. La tendencia de estos desarrollos en la sociedad civil es a incrementarse, dada la relevancia que están obteniendo en su dinámica las redes sociales. Este florecimiento debe no solo protegerse, sino también incentivarse.

Finalmente, la aportación de este trabajo no solo reside en la aplicación de la teoría de la IC y del análisis efectuado sobre sus efectos en el Salvador, sino en la utilidad del modelo construido, el cual puede ser aplicado a cualquier estudio de caso. Este instrumento resultará de mucha ayuda en el estudio de la IC, al permitir dilucidar y analizar los actores que lo configuran, la dinámica en que se interrelacionan y su grado de evolución. A fin al cabo, la IC es una amenaza que puede aparecer en cualquier Estado y sociedad pero esta realidad no debe eximir de la responsabilidad de tomar las medidas que permitan minimizar su alcance. "La sabiduría consiste en saber cuál es el siguiente paso; la virtud, en llevarlo a cabo" (Jordan).

\section{Referencias}

AFP. (28 de enero de 2007). Arzobispo salvadoreño deplora fuga de diputado narco. Radio La Primerísima.

Aguilar, J. (10 de diciembre de 2011). EUA aseguró que el PCN y GANA reciben dinero a cambio de sus votos. El FARO. AFP. (28 de enero de 2007). Arzobispo salvadoreño deplora fuga de diputado narco . Radio La Primerísima.

Albanese, J. S. (2008). Risk Assessment in Organized Crime: Developing a Market and Product Based Model to Determine Threat Levels. Journal of Contemporary Criminal Justice, 24(3), 263-273.

AP. (06 de agosto de 2011). 31 años de cárcel para el Capitán Muerte por tráfico de armas. El Diario de Hoy.

AP. (07 de abril de 2012). Inteligencia Guatemalca Zetas reclutan a pandilleros. El Diario de Hoy. 
Arnson, C. J., \& Olson, E. L. (2012). Organized Crime in Central America: The Northern Triangle. Washingyon D.C.: Woodrow Wilson International Center for Scholars.

Ávalos, J. (31 de agosto de 2012). CSJ acumula 1,085 denuncias contra jueces. La Prensa Gráfica.

Ávalos, J. (27 de septiembre de 2012a). Especializados suspendieron 20 audiencias. La Prensa Gráfica.

BA. (2012). Barometro de las Américas (BA). Proyecto de Opinión Pública para América Latina, Universidad de Vanderbilt.

Baires Quezada, R. \& Martínez, C. (15 de abril de 2009). Adolfo Torres pidió medio millón a Roberto Silva liberarlo de cargos en El Salvador. Periódico Digital EL FARO.net

Baires Quezada, R. (11 de agosto de 2011). Safie, el sabueso que se esfumó. EL FARO Diario Digital.

Benítez Manault, R. (2012). Crimen Organizado, Seguridad Nacional, Democracia y Elecciones. Seguridad y Sociedad, 1(4),5-7.

BGC. (2011). Barómetro Global de Corrupción (BGC) 2010/2011. Transparencia Internacional.

Brandão, T. D. (2008). Organizações Criminosas no Brasil: umaAnálise a partir da teoria das Elites e da Teoria da Ação Coletiva. Revista Eletrônica Inter-Legere (3), 1-18.

Bunck, J. M., \& Ross Fowler, M. (2012). Bribes, Bullets and Intimidation: Drug Trafficking and the Law in Central America. PA: Penn State Press.

Cabrera , A. (31 de mayo de 2012). Barahona en la mira de la Asamblea Legislativa. La Prensa Gráfica.

Cabrera, A. (24 de octubre de 2012a). Derecho a la información esta desprotegido dice ISD. La Prensa Gráfica.

Chávez, S. (15 de noviembre de 2011). FGR investiga desaparición de 8,000 granadas. La Prensa Gráfica.

Chávez, S. (25 de junio de 2012a). El empresario que quería hacer jabón. La Prensa Gráfica, pp. 10 y 12.

Chávez, S. (27 de noviembre de 2012b). Juzgados Especializados acumulan casos de homicidios. El Diario de Hoy.

Chávez, S. (24 de junio de 2012c). El Salvador trampolín de precursores. La Prensa Gráfica.

Chêne, M. (2008). Organised crime and corruption. Anti-Corruption Research Center, Transparency International. 
Córdova Macías, R., \& Cruz, J. (2010). Cultura Política de la Democracia en El Salvador. El Salvador: Latin American Public Opinion Project (LAPOP), Vamderbilt University.

Delhi, N. (19 de diciembre de 2009). EE.UU pide a El Salvador agilice entre 12 y 15 extradiciones. PanamaAmerica.com.pa

DOD. (2012). La Politica de Defensa para el Hemisferio Occidental. Washington D.C.: Departamento de Defensa, EEUU.

Đorđević, S. (2009). Understanding transnational organized crime as a Security threat and Security Theories. Western Balkans Security Observer, (13), 39-52.

DPLF; FESPAD;. (2012). Informe sobre la situación de la independencia judicial en El Salvador, Fundación para el Debido Proceso (DPLF) y la Fundación de Estudios para la Aplicación del Derecho (FESPAD). Audiencia temática en el 144 período ordinario de sesiones de la Comisión Interamericana de Derechos Humanos.

EDH. (17 de noviembre de 2010). Testigo clave ratifica que Silva y Manolillo planearon la masacre. El Diario de Hoy (EDH).

EDH. (14 de noviembre de 2011a). Banda Los Perrones compra inmuebles en Cuba e invierte en turismo en Roatán, Honduras. El Diario de Hoy (EDH).

EDH. (13 de diciembre de 2011b). Dueños de furgones con salarios de $\$ 11$ y \$15 doláres diarios. El Diario de Hoy (EDH).

EDH. (14 de noviembre de 2011c). Los Narcos del Oriente salvadoreño reciben droga de submarinos y lavan dinero en Cuba. El Diario de Hoy (EDH).

EDH. (13 de febrero de 2011d). Salvadoreños compran terrenos en Nicaragua. El Diario de Hoy.

EDH. (23 de enero de 2011e). Bajo investigación nueve policías ligados a los Zetas. El Diario de Hoy (EDH).

EDH. (20 de diciembre de 2012). EDH. El Diario de Hoy (EDH).

EL FARO. (26 de marzo de 2007). Un diputado parece que es el jefe de un cartel de narcos en Guatemala. Diario Digital EL FARO.

EL FARO. (16 de mayo de 2011). El Cártel de Texis. Diario Digital EL FARO. Ellis, R. E. (2012). Organized Crime Exploits China's Growing Links to Latin America. China Brief, XII, (11), 2012, 6-8. 
Embajada de EE.UU El Salvador. (2009). Reorganizing ARENA: Theparty's future after Avila's defeat. cable diplomático secreto, 06 de octubre de 2009, WikiLeaks, Id No. 09SANSALVADOR947.

Embajada de los EE.UU El Salvador. (2008). ¿Qué fue lo que consultaste? Recuperado de http://sansalvador.usembassy.gov/reports/2008/ ncs/vol-ii2.html.

Equipo de Investigación. (11 de julio de 2007). La Estructura que Otto Herrera montó. El Periodico.

Evera, S. V. (1997). Guide to Methods for Students of Political Science. Ithaca yand Londresdon: Cornell University Press.

Fantz, A. (2012). The Mexico drug war: Bodies for billinos. Recuperado de CNN. com. http://edition.cnn.com/2012/01/15/world/mexico-drug-waressay/index.html.

Farah, D. (2011). Organized Crime in El Salvador: The Homegrown and Transnational Dimensions. Working Paper Series on Organized Crime in Central, Woodrow Wilson International Center for Scholars.

Fernández, L., \& Jara, M. (15 de noviembre de 2010). Llevaban \$5 Millones. Diario El Mundo.

Flores, R. (12 de diciembre de 2012). Indagan Red de Contrabando en Región C.A. La Prensa Gráfica.

Flores, R. (10 de mayo de 2012a). Las pandillas podrían llegar a convertirse en carteles: Payés. La Prensa Gráfica.

Funes Cartagena, M. (2011). Discursos $66^{\circ}$ y $67^{\circ}$ Sesiones Asamblea General de las Naciones Unidas, 23 de septiembre 2011 y 25 septiembre 2012. Nueva York.

García, E. (10 de diciembre de 2012). 2,300 homicidios menos en 2012 confirma Mijango. El Mundo.

García, E. (09 de noviembre de 2012a). PNC sospecha que la droga seria traficada por la MS. El Diario de Hoy.

Godson, R. (2003). Menace to Society; Political Criminal Collaboration around the world. New Jersey: National Strategy Information Center, Transaction Publishers, Rutgers.

Greenhill, K. M. (2009). Kleptocratic Interdependence: Trafficking Corruption and The Marriage of Politics and Illicit Profits. En R. I. Rotberg, Corruption, Global Security and World Order, (pp. 96-123). Baltimore: Brookings Institution Press. 
Ho, Y.-H., \& Huang, C.-J. (2011). The Corruption-Economic growth nexus: Evidence from Four Bric Countries, based on the Panel Data Approach. Journal of Global Business and Technology, 7(2) 44.

International Budget Partnership. (2010). Encuesta de Presupuesto Abierto 2010. Washington D.C.: International Budget Partnership.

IPC. (2012). Índice de Percepción de Corrupción (IPC). Berlín: Transparencia Internacional.

Iraheta, O., Quintanilla, L., Segovia, C., \& Mendoza, I. (21 de septiembre de 2012). Retrasan una semana salarios a policías por falta de fondos. El Diario de Hoy.

Keohane, R. O., \& Nye, J. S. (2000b). Power and Interdependence (3 Ed.). New York: Longman, 3rd.ed.

Killebrew, B., \& Bernal, J. (2010). Crime Wars: Gangs, Cartels and National Security. Ciudad: American Security.

Knudson, J. W. (1993). Late to the Feast: Newspapers as Historical Sources. Perspectives Online, 5(1), 69-98.

Kruger, R. L. (2006). Policy Analysis in National Security Affairs: New Methods for a New Era. Washington DC: Center for Technology and National Security Policy, National Defense University.

La Red. (2011). Seguridad y Crimen Organizado Transnacional: Una propuesta de Acción para Centroamérica. Guatemala: La Red Centroamericana de Centros de Pensamiento e Incidencia,Fundación Konrad Adenauer.

La Red. (2012). Siguiendo la Ruta del Dinero en Centroamérica: Lavado de Dinero y sus Implicaciones a la Seguridad Regional. Junio: Red Centroamericana de Centros de Pensamiento e Incidencia, Konrand Adenauer Stiftung. LAPOP. (2012). Barometro de las Américas. Proyecto de Opinión Pública para América Latina (LAPOP), Universidad de Vanderbilt.

Latinobarómetro. (2011). Informe 2011. Santiago: Corporación Latinobarómetro.

López, J., \& Iraheta, O. (08 de agosto de 2012). Segunda demanda en FGR contra Ovidio Bonilla. El Diario de Hoy.

LPG. (11 de enero de 2011a). EUA valida 14.6 millones de narco doláres. La Prensa Gráfica (LPG).

LPG. (11 de junio de 2011b). Oficiales de PNC involucrados en asesinato de informante de la DEA. La Prensa Gráfica (LPG).

LPG. (14 de diciembre de 2012a). Costa Rica detiene a salvadoreño con coca. La Prensa Gráfica (LPG). 
LPG. (30 de julio de 2012b). La droga que dejan aquí es dañada. La Prensa Gráfica (LPG).

LPG. (05 de julio de 2012c). Centro de Escuchas sin participación de la Policía. La Prensa Gráfica (LPG).

Magaña, Y. (19 de septiembre de 2012). Corte tiene 5.,259 casos pendientes en sus salas. Diario ElMundo.

Magaña, Y. (27 de noviembre de 2012a). Relatora de la ONU pide no atentar contra la Sala. Diario El Mundo.

Marroquín, D. (09 de noviembre de 2012). Narcos dejan lancha con más de 113 kilos de cocaína en Metalío. El Diario de Hoy.

Marroquín, D. (12 de mayo de 2012a). EE.UU pide uso de escuchas y confiscación de bienes ilícitos. el Diario de Hoy.

Marroquín, D. (29 de diciembre de 2012b). Policía Antidrogas ha confiscado mas de 16 millones de dólares en los últimos tres años. ElDiario de Hoy.

Membreño, T. (19 de enero de 2012a). Millonario decomiso de moneda falsa. La Prensa Gráfica.

Membreño, T., \& Flores, R. (18 de febrero de 2012b). Ministros de Seguridad Preparan Plan Regional. La Prensa Gráfica.

Membreño, T., \& Flores, R. (05 de diciembre de 2012b). Salinas confirma pesquisas sobre policías por drogas. Prensa Gráfica.

Menjívar, V., Mejía, A., \& Romero, F. (15 de febrero de 2013). Políticos avalan Ley de Partidos Políticos sin dientes. La Prensa Gráfica.

Milian, J. H. (2008). El Crimen Organizado en América Latina y el Caribe: Mapeo del Caso Centroamericano. Ponencia presentada en elMéxico DF: Seminario El Crimen Organizado América Latina y el Caribe, Amenazas y Perspectivas, Friedrich Ebert, lugar en el que se realizó el evento, México D.F.

Morales, J. J. (06 de mayo de 2012). Las redes sociales: el nuevo cuarto poder». El Diario de Hoy.

Naim, M. (2003). The Five Wars of Globalization. Foreign Policy, 29-36.

ONU. (2004). Convención de Naciones Unidas contra la Delincuencia Organizada Transnacionaly sus Protocolos. Nueva York: Naciones Unidas (ONU).

Orellana, L. (12 de noviembre de 2012). Piden publicar nombres de donantes partidiarios. Diario El Mundo.

PEN. (2011). Informe IV Estado de la Región. Recuperado de http://www. estadonacion.or.cr/index.php/biblioteca-virtual/centroamerica/ 
informe-actual/informe-por-capitulo/capitulo-6-actual-ca, Cap. 6, pg. 377.: Programa Estado de Nación (PEN).

Quintanilla, L. (06 de diciembre de 2012). Estudio revela que pandillas ingresan $\$ 60$ millones. La Prensa Gráfica.

Randers, J. (1980). Guidelines for Model Conceptualization. En J. R. (ed), Elements of the System Dynamics Method (pp. 117-139). Cambridge: Productivity Press.

Redacción de Nación. (01 de diciembre de 2012a). Furgoneros en la mira del Narcotráfico. La Prensa Gráfica.

Redacción Nación. (28 de mayo de 2012b). Capturan a acusado de traficar droga en la zona norte. La Prensa Gráfica.

Rocha, J. L., Brown, E., \& Cloke, J. (2011). Of legitimate and illegitimate corruption. Critical Perspectives on International Business, 7(2), 159-176.

Romero, F. (08 de octubre de 2012). Gobierno descubre 307 casos de posible corrupción. La Prensa Gráfica.

Romero, F., \& Gómez, A. (23 de junio de 2011). Funes: hay infiltración en el Ejército y Policía. La Prensa Gráfica.

Rotberg, R. I. (2009). Corruption, Global Security and World Order. Baltimore: Brookings Institution Press.

Rothstein, B. (2011). The Quality of Goverment: Corruption, Social Trust, and Inequality in International Perspective. Chicago: The Unversity of Chicago Press.

Ruhl, M. J. (2011). Political Corruption in Central America: Assessment and Explanation. Latin American Politics and Society, 53, (1), 33-58.

Salguero, M. (21 de junio de 2012). Barahona: Centro de Escuchas ya Funciona. La Prensa Gráfica.

Senge, P. M. (1990). The Fifth Discipline: The Art and Practice of the Learning Organization. Nueva York: Doubleday.

Shelley, L. (2001). Crime Victimizes both Society and Democracy. Fairfax: Transnational Crime and Corruption Center, American University.

Soriano, A., \& Rivera, E. (05 de diciembre de 2012). Eligen a fiscal. Diario ElMundo.

State Department. (2011). Country Report on Human Rights Practices El Salvador.

State Department. (2012). Money Laundering and Financial Crimes Country Database. Ciudad: Bureau for International Narcotics and Law Enforcement Affairs. 
Suchit, C. (02 de marzo de 2012). Acelerado crecimiento alertó a FGR. La Prensa Gráfica.

UIFP. (2012). Tipologías de lavado de Activos. Recuperado de http://www. sbs.gob.pe/RepositorioAPS/0/2/jer/DOCIMP_INTERNACIONALES/tipologias.pdf. : Unidad de Inteligencia Financiera del Perú. Underkuffler, L. S. (2009). Understanding Corruption: Minstream Theories. En R. I. Rotberg, Corruption, Global Security and World Order (pp. 27-46). Baltimore: Brookings Institution Press.

Valencia Caravantes, D. (27 de junio de 2011). Las 1.800 granadas y el mayor que se esfumó. Diario Digital EL FARO.

Velásquez, E. (25 de noviembre de 2012). Se cumplio un año y no hay Instituto de Acceso a la Información. El Diario de Hoy.

Velásquez, E., \& Díaz, P. (30 de noviembre de 2010). Silva: 4 añnos en limbo legal. La Prensa Gráfica.

Velásquez, J. C. (09 de agosto de 2012). Chepe Luna con expedientes abiertos FGR El Salvador. Diario El Mundo.

WH. (2011). Presidential Memorandum- Major Illicit Drug Transit Fiscal Year 2012. Washington D.C.: The White House (WH), Office of the Press Secretary.

Wilgoren, D. (19 de enero de 2006). 29 años EEUU sentencia ex-diputado. Washington Post publicado por El Diario de Hoy.

Williams, P. (1994). Transnational Criminal Organizations: Strategic Alliances. The Washington Quarterly.

Williams, P. (2001). Transnational Criminal Networks. RAND Corporation.

Williams, P. (2012 a). Lawlessness and Disorder: An Emerging Paradigm for the Twenty-First Century. documento sin publicar proporcionado por el autor. Williams, P. (2012 b). Crimen Organizado Transnacional definiendo la Amenaza. Bogotá, Colombia: Ejercicio Fuerza Comando, Comando Sur EEUU, mayo 2012.

WJP. (2012). World Justice Project (WJP) Rule of Law Index. Washington: The World Justice Project.

WOLA. (2011). Organized Crime and State Corruption: The Challenge in El Salvador, the Experience in Guatemala. Washington D.C.: Washington Office for Latin America (WOLA). 


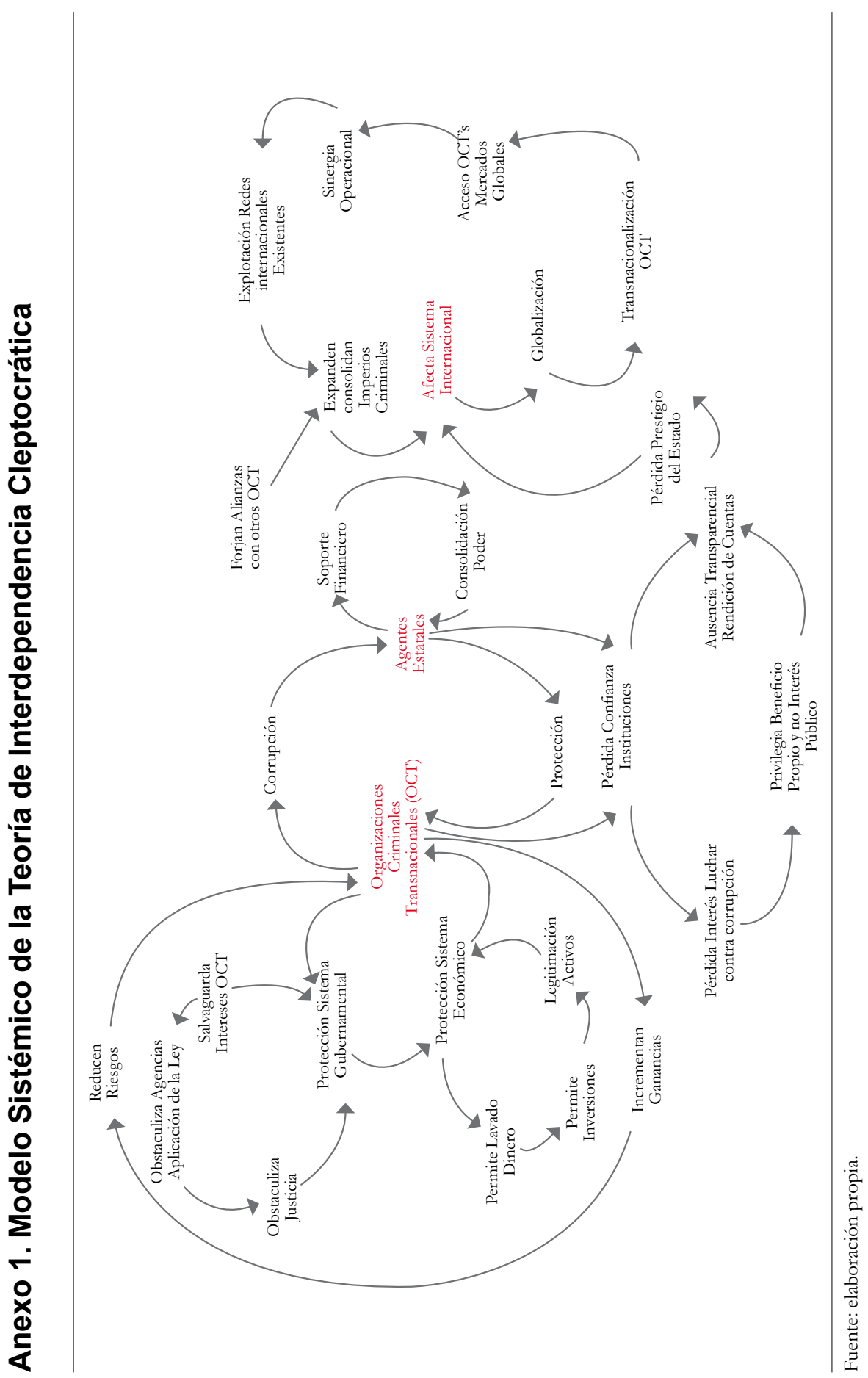


